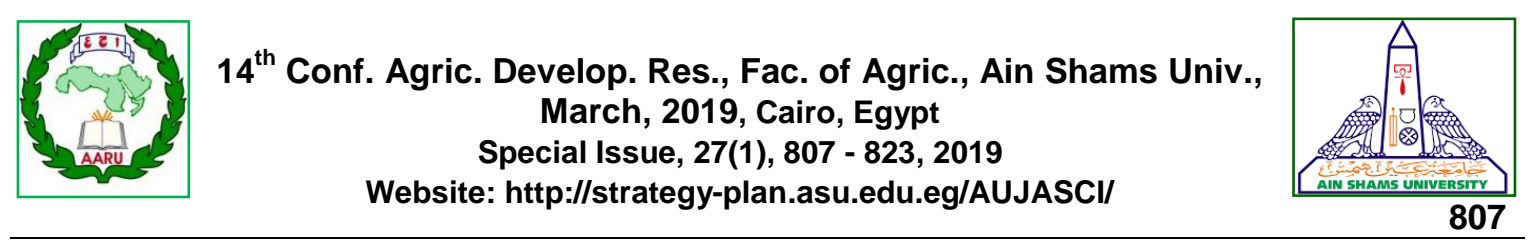

\title{
CHEMICAL CONTROL OF GUAVA DIE-BACK AND RESPONSE OF GUAVA CULTIVARS TO THE DISEASE IN EGYPT
}

\author{
Abd El-Aziz, A.S. \\ Plant Pathology Research Institute, Agric. Research. Cent., Giza, Egypt. \\ *Corresponding author: ahmed.sabry617@yahoo.com
}

Received 30 January, 2019, Accepted 11 March, 2019

\section{ABSTRACT}

Guava (Psidium guajava L.,) die-back disease caused by Botryodiplodia theobromae Pat., is a destructive disease, considered one of the most important and economic disease of guava. Amistar Top 325-32.5\% E.C. gave the highest decreasing of linear growth and amount of growth of isolate code No., Q.K.4., followed by Camzin 50\% W.P., Monceren 25\% W.P. and Montro 30\% E.C. Meanwhile, Ridomil Gold/Plus 42.50\% W.P., Copral 50\% W.P., Eminent $12.50 \%$ E.W. and Thiovat Jet $80 \%$ W.G. exhibited a lowest effect in reducing of linear growth and amount growth of $B$. theobromae isolate code No., Q.K.4. Amistar Top 325-32.5\% E.C was the most efficient fungicide in reduce disease incidence and disease severity infield of $B$. theobromae isolate code No., Q.K.4., followed by Camzin 50\% W.P., Monceren 25\% W.P., Montro 30\% E.C. Meanwhile, Ridomil Gold/Plus $42.50 \%$ W.P., Copral 50\% W.P., Eminent $12.50 \%$ E.W. and Thiovat Jet $80 \%$ W.G. showed a lowest efficient in reducing the disease incidence and disease severity. Soil drench method of fungicides application was the higher efficient method in elimination of percentage of disease incidence and disease severity followed by foliar spray application, relatively. Banaty transplant was the most susceptible cultivar to the all tested $B$. theobromae isolates, whereas cultivar Gizy Ahmr was the lowest susceptible with the same isolates, information about cultivar reaction of guava transplants against $B$. theobromae is still scanty.

Key words: Guava, Psidium guajava L., Botry odiplodia theobromae Pat., Guava Die-back, Chemical Control, cultivar reaction

\section{INTRODUCTION}

Guava trees (Pisidium guajava L.,) suffer from several serious and destructive diseases at all stages of its life. Several fungi attack guava causing seedling root rots (Baiuomy et al 2003), anthracnose (Dharam and Gaur, 1973), black spot (Mishra and Sitansu, Pan, 2007), stem canker (Cardoso et al 2002, Kamhawy, 2011), stem-end rot (Mishra and Sitansu, Pan, 2007), die-back (Bokhari et al 2008, Safdar, Asma et al 2015) and wilt diseases (Pandit and Samajpati, 2002; Pandit and Samajpati, 2005, Dwivedi, Neetu and Dwivedi, 2016).

Under the Egyptian environmental conditions, several most important serious diseases attack guava foliage, roots and fruits. Guava die-back disease an important and economic serious problem causing severe losses in both nurseries and orchards in Egypt (Abdel-Gawad, 2000, Baiuomy, et al 2003 and Kamhawy, 2011 and Rashed et al 2014).

Guava die-back is a complex disease to extensive root rot caused by Botryodiplodia theobromae Pat. on the shoot causing fruit rot (Rana, 1981, Adisa, 1985, Rawal and Ullasa, 1988, Majumdar and Pathak, 1997 and Baiuomy, et al 2003), fruit Botryodiplodia rot (Junqueira, 2001), fruit dry rot (Rana, 1981, Sitansu, Pan and Mishra, 2010), die back. The typical symptoms of guava die-back disease include chlorosis, scorching of leave margins and leaf drop, yield reduction and plant death within months caused by Botryodiplodia theobromae Pat. Several investigators have been recorded that Botryodiplodia theobromae Pat. is a soil borne phytopathogen fungus and attack guava trees and wide spread in the world (Rana, 1981, Mishra and Sitansu, Pan, 2007 and Kamhawy, 2011 and Safdar, Asma et al 2015). 
Although the recent strategy of control plant diseases is depend upon minimizing of fungicidal utilization to avoid environmental pollution and keep human health, fungicides are one of Integrated Pest Management (IPM) weapons, fungicides are still one of the most important means to control the causal pathogens of different diseases either in in vitro or in in vivo, accordingly this trials were carried out to the present study. The effect 24 fungicides differed in their active ingredients and chemical groups including systemic and nonsystemic ones were tested on Botryodiplodia theobromae growth and their efficiency on the die-back disease.

Information about cultivar reaction of guava transplants against Botryodiplodia theobromae is still scanty. Cultivar reaction of guava trees is one of the most important factors affecting percentage of disease incidence and disease severity of guava die-back disease and considered one of Integrated Pest Management (IPM) weapons to control the causal pathogens of different diseases.

The strategies of the present study were designed to chemical control against Botryodiplodia theobromae Pat., the causal agent of guava dieback disease, as well as response of guava cultivars to the disease were also investigated.

\section{MATERIALS AND METHODS}

In a previous study; Botryodiplodia theobromae Pat. isolate Q.K.4 was the highest pathogenic to produce typical symptoms of guava die-back under greenhouse conditions. Such isolate was used throughout of this study (the author, in Press).

\section{Inocula preparation}

Discs $5 \mathrm{~mm}$. of the mycelial growth of the pathogen was taken from 7 days old cultures of Q.K.4 isolate of $B$. theobromae Pat. grown on PDA medium. Each disc was set on the surface of sterilized corn meal medium in each $500 \mathrm{ml}$. glass bottle. Corn meal medium was prepared by adding $200 \mathrm{~g}$. of corn meal to $100 \mathrm{~g}$. sand and $200 \mathrm{ml}$. water in each glasses bottles $(500 \mathrm{ml}$.). All bottles were autoclaved at $120^{\circ} \mathrm{C}$ for one hour at $1.5 \mathrm{IB}$ square inches. A set of 5 bottles were used as replicates of each treatment. A set of 5 bottles of sterilized corn meal sand medium were used without fungal inoculation as control treatment. All inoculated as well as uninoculated bottles were incubated at $25 \pm 2^{\circ} \mathrm{C}$ for two weeks to obtain sufficient mycelial growth of different isolates.

\section{Soil infestation}

Soil infestation was carried out using corn meal inoculated with a $5 \mathrm{~mm}$. disc from isolated $B$. theobromae (Q.K.4) isolate taken from 7 days old cultures. Plastic pots $25 \mathrm{~cm}$. in diameter were sterilized by immersing in 5\% formalin solution for 15 minutes and left to dry for two weeks for complete evaporation of formalin, and then were filled with autoclaved at $120^{\circ} \mathrm{C}$ for one hour at $1.5 \mathrm{IB}$ square inches; sand and clay soil mixture (1: $1 \mathrm{w} / \mathrm{w})$ was prepared for soil infestation. Both sterilized pots and soil mixture were left for few days under greenhouse before infestation. The prepared inocula of the fungus on corn meal medium were mixed individually with the autoclaved soil sand mixture at the rate $5 \%(\mathrm{w} / \mathrm{w})$. The inoculum was thoroughly mixed with the upper surface of soil and irrigated regularly 7 days before planting homogenous guava transplants to ensure the establishment of tested isolate. Thirty infested plastic pots (each pot contained $5 \mathrm{~kg}$. of soil sand mixture) were used for isolate (Q.K.4). The soil was infested with isolate at the rate $5 \%$ of soil weight. Control treatment was applied using fungus free corn meal medium. One guava transplant cultivar Banaty (one year old) was cultivated in each pot. Five pots were replicates used for each treatment; each treatment contained six guava transplants. Plants were examined for guava die-back disease after 15, 30, 45 and 60 days from inoculation. Pots were arranged in complete randomized design. Re-isolation from inoculated guava transplants was made as mentioned before, to confirm Koch's postulates.

Chemical Control of Botryodiplodia theobromae Pat., the causal pathogen of guava dieback disease

\section{Laboratory studies (in in vitro experiments)}

\subsection{Effect of fungicides on mycelial linear growth (mm.)}

Accordingly, these trials were carried out to study the effect of twenty four fungicides differed in their active ingredients and chemical groups including, systemic and non-systemic fungicides ones (Table 1).

The calculated quantity of each fungicide for each concentration was weighed and dissolved in $5 \mathrm{ml}$. of distilled water and made up to $100 \mathrm{ml}$, $25 \mathrm{ml}$. of each concentration was added to each plate $(9 \mathrm{~cm}$.) in the freshly prepared PDA (Potato 
Dextrose Agar) separately and allowed to cool to a pouring temperature of $40-45^{\circ} \mathrm{C}$. Twenty five $\mathrm{ml}$. of these PDA amended with different fungicide at different concentration poured into $9 \mathrm{~cm}$. in diameter sterilized petri dishes. Each plate including the control (without fungicide) on solidification PDA medium was inoculated in the middle with uniform mycelial disc $(5 \mathrm{~mm}$. in diameter) of the most virulent isolate of Botryodiplodia theobromae code (No. Q.K.4) obtained from 7 days old culture by using sterilized inoculating needle. Each concentration of each fungicide including control (media without any fungicides) were placed in an incubator at $25^{\circ} \mathrm{C} \pm 2$ for 7 days and observed daily for mycelial growth. Radial mycelial growth was measured when growth of control treatment completely filled any plate.

Five glass petri-dishes $9 \mathrm{~cm}$. in diameter were used for each particular concentration as well as, control treatment (media without any fungicides).

\subsubsection{Effect of fungicides on amount of myceli- al growth (mg.)}

The effect of twenty four tested fungicides (Table 1) on the amount of mycelial growth was studied of the most virulent isolate of Botryodiplodia theobromae code (No. Q.K.4) investigated by using eleven different used concentrations i.e., 0,5 , $10,25,50,100,200,300,400,500$ and 600 ppm. of each tested fungicide were prepared according to (Sharvell, 1962) to determine their ability to inhibit the amount of mycelial growth. One hundred $\mathrm{ml}$. of sterilized Czapek's broth medium were placed in glass Erlenmeyer conical flasks (250ml. capacity) five replicates of each concentration for each fungicide (treatment) were inoculated with mycelial disc $5 \mathrm{~mm}$. in diameter obtained from 7 days old culture of the desired of the most virulent isolate of Botryodiplodia theobromae code (No. Q.K.4). All glass Erlenmeyer conical flasks were incubated at $25^{\circ} \mathrm{C} \pm 2$ for 7 days. Fungal mates were collected on previously weighed filter papers, washed with distilled water, dried at $70^{\circ} \mathrm{C}$ for constant weight and weighed. The amount of mycelial growth of each tested fungicide for each concentration was determined. Data was being the average of five single determinations.

\section{In vivo evaluation the efficacy of different fungicides against guava die-back disease in pot experiments under greenhouse conditions}

The same twenty four tested different fungicides in laboratory studies (in in vitro experiments) were used to evaluate their efficiency against guava die-back disease on cultivar Banaty. Homogenous transplants one year old were cultivated in pots $(25 \mathrm{~cm}$.). Pots contained infested soil with isolate Q.K.4 of the pathogen. One transplant was culitved for each pot. By using rates of application (as recommended dose) of each tested fungicides. The different fungicides (Table 1) were applied by two methods; soil drench and foliar spray to determine their efficacy of reduction the disease incidence and disease severity of guava die-back disease.

Meanwhile a set of pots containing autoclaved soil mixture used as control treatment was amended a mixed with fungus-free corn meal medium (uninoculated corn meal medium). Pots were filled with either of the mixture as required. Guava transplant cultivar Banaty (one year old) were surface sterilized by using $2 \%$ sodium hypochlorite solution for one minute, washed with sterilized distilled water, then one transplant was planted in each plastic pots $(25 \mathrm{~cm}$. in diameter) containing soil mixture infested with the tested Botryodiplodia theobromae isolate code (No. Q.K.4). Percentage of toxicity was calculated according to the formula suggested by (Topps and Wain, 1957) as the following:

Toxicity or reduction of disease incidence or disease severity $\%=\frac{\mathbf{B}-\mathbf{A}}{\mathbf{B}} \times 100$.

Where:

$A=$ disease incidence or disease severity after fungicides application (treatment).

$\mathrm{B}=$ disease incidence or disease severity before fungicides application (control).

\subsection{Soil drench application}

The same twenty four fungicides tested in laboratory studies were used to evaluate their efficiency in pot experiments under greenhouse conditions against guava die-back disease of cultivar Banaty one year old by using rates of applications (as recommended dose) of each tested fungicides individually were used as suspensions by solving rates of application (as recommended dose) of each tested fungicides per liter of water for each plastic pot $(25 \mathrm{~cm}$. in diameter). The percentage of disease incidence and disease severity were assessed before the application with fungicides treatment.

One transplant per/pot and pots soil were drenched with one liter of each fungicidal suspension or solution to saturate the pots soil and main- 
tain a $1-\mathrm{cm}$. layer of fungicidal suspension or solution over the surface for one time.

Five replicates for each treatment; each replicate contained six homogenous guava transplants one year old, planted in six pots (one transplant per/pot) and also a set of pots for the control treatment (treated with water only without any fungicides), soil drench treatment was applied for one time. Pots were kept for 60 days under greenhouse conditions at $25^{\circ} \mathrm{C} \pm 2$ and irrigated regularly with tap water as needed used for each treatment. After 60 days from fungicidal soil drench treatment, the disease incidence and disease severity were assessed.

\subsection{Foliar spray application}

The same twenty four fungicides tested in laboratory studies were used to evaluate their efficiency in pot experiments under greenhouse conditions against guava die-back disease of cultivar Banaty one year old, infected previously with the most virulent isolate of Botryodiplodia theobromae code (No. Q.K.4), the same method in pathogenicity test of inoculation was used as mentioned before. By using rates of applications (as recommended dose) of each tested fungicides. Each plastic pot $(25 \mathrm{~cm}$. in diameter) were covered with plastic sheet upon soil surface to prevent solutions or suspensions of tested fungicides from fall into soil of each pot and fungicides were used a suspension by solving rates of application (as recommended dose) of each tested fungicides per liter of water and were sprayed from all direction until runoff by using a normal manual pressure sprayer 1.5 liter in size separately for one time. The percentage of disease incidence and disease severity were assessed before the application with fungicides treatment.

Five replicates for each treatment, six homogenous transplants for each replicate (one guava transplant per/pot), the same number of guava transplants were grown in infested soil, also, a set of pots treated with water only without any fungicides as a control (treatment). Pots were kept for 60 days under greenhouse conditions at $25^{\circ} \mathrm{C} \pm 2$ and irrigated regularly with tap water as needed used for each treatment. After 60 days from fungicidal foliar spray treatment, the disease incidence and disease severity were assessed, and the reduction of the percentage of disease incidence \% D.I. and percentage of disease severity \% D.S. were calculated as mentioned previously in soil drench application.

\section{Cultivar reaction}

The reaction of four guava transplant cultivars i.e., Banaty, Malisy Ahmr, El-Mobaker and Gizy Ahmr one-year-old were kindly obtained from Production Unit of Fruit Section, Horticulture Research Institute, Agriculture Research Center (ARC) were used in this investigation to infection with ten isolates of Botryodiplodia theobromae Pat. which were characterized in a previous study (the author, in Press) i.e., code numbers B.W.1, A.B. 2, D.S. 3, Q.K. 4, A.A. 5, B.N. 6, K.Q. 7, Q.S. 8, D.B. 9 and K.D. 10 were evaluated in plastic pots experiment under greenhouse conditions of each cultivar.

All Botryodiplodia theobromae isolates associated with guava die-back symptoms used for testing pathogenicity on guava transplants cultivars for pathogenicity screening against the isolates of Botryodiplodia theobromae and mentioned under greenhouse conditions (10-14h. light-and- dark cycles) at $25^{\circ} \mathrm{C} \pm 2$. Five replicates for each treatment, each treatment contained six homogeneous guava transplants for each cultivar individually one transplant for each pot and the same number for each cultivar of guava transplants individually was used in control treatment and pots were arranged in a randomized design.

\subsection{Inocula preparation}

Discs $5 \mathrm{~mm}$. of the mycelial growth of different isolated Botryodiplodia theobromae Pat. isolates were taken from 7 days old cultures on PDA medium. Each disc was set in the surface of sterilized corn meal medium in each $500 \mathrm{ml}$. glass bottle. Corn meal medium was prepared by adding $200 \mathrm{~g}$. of corn meal to $100 \mathrm{~g}$. sand and $200 \mathrm{ml}$. water in each glasses bottles $(500 \mathrm{ml}$.). All bottles were autoclaved at $120^{\circ} \mathrm{C}$ for one hour. A set of 5 bottles were used as replicates of each isolate. A set of 5 bottles of sterilized corn meal sand medium were used without Botryodiplodia theobromae Pat. isolates inoculation as control treatment. All inoculated as well as uninoculated bottles were incubated at $25 \pm 2^{\circ} \mathrm{C}$ for two weeks to obtain sufficient growth of different isolates.

\subsection{Soil infestation}

Soil infestation was carried out using corn meal inoculated with a $5 \mathrm{~mm}$. disc from each of Botryodiplodia theobromae Pat. isolates taken from 7 days old cultures. Pots of $25 \mathrm{~cm}$. in diameter were sterilized with $5 \%$ formalin solution and left for a 
week for formalin evaporation, then were filled with autoclaved sand and clay soil (1: $1 \mathrm{w} / \mathrm{w})$. The soil was infested with each isolate alone at the rate of $5 \%$ of soil weight. The inoculum was thoroughly mixed with the upper surface of the soil and irrigated regularly seven days before planting to ensure the establishment of the isolates.

A set of pots as control treatment were applied using free from any Botryodiplodia theobromae isolate corn meal medium. One guava transplant, cultivar Banaty, Malisy Ahmr, El-Mobaker and Gizy Ahmr (one year old) were cultivated for each cultivar individually, one transplant planted in each pot and five replicates were used for each treatment, each treatment contained six homogeneous guava transplants. All transplants were examined for guava die-back disease after 15, 30, 45 and 60 days after inoculation. Re-isolation from inoculated guava transplants was made as mentioned before, to confirm Koch's postulates.

\section{Disease assessment}

A method of visual estimation of the disease was assessed on samples consisted 160 guava trees from each inspected locality where used for assign disease. The disease incidence (D.I.) and the disease severity (D.S.) percentages were calculated for each season through the following formula (Cooke et al 2006).

$$
\% \text { Disease incidence (D.I.) }=\frac{\Sigma \mathrm{x}}{\mathrm{N}} \times 100
$$

Where:

$\Sigma \mathrm{x}=$ sum number of diseased transplants; $\mathrm{N}=$ total number of inspected transplants

$$
\begin{aligned}
& \% \text { Disease severity (D.S.) }=\frac{\Sigma(\mathrm{nxv})}{\mathrm{Nx}} \times 100 \\
& \text { Where: } \\
& \mathrm{n}=\text { number of examined transplants; } v=\text { numer- }
\end{aligned}
$$
ical rating of the scale $(0-4) ; \mathrm{N}=$ total number of transplants; $x=$ maximum value (5) of evaluation scale

Disease reading was determined for each transplant according to the disease severity rating by determing the area of infected part to include the diameter of the area of the transplant. The following numerical rates were suggested for disease severity:

$0=$ healthy transplants, no symptoms; $1=1$ $25 \%$ infected part of the transplants; $2=26-50 \%$ infected part of the transplants; $3=51-75 \%$ infected part of the transplants; $4=76-100 \%$ infected part of the transplants

\section{Statistical Analysis}

All experiments were laid out in a completely randomized design (C.R.D.) there were five replicates for each treatment; each treatment contained six homogenous guava transplants, one transplant planted per/plastic pot $(25 \mathrm{~cm}$. in diameter) experiment under greenhouse conditions.

Statistical Analysis carried out in Agricultural Informatics And Arithmetic Unit, Faculty Of Agriculture, Ain Shams Univ. Data were subjected to ANOVA by using SAS statistical software (SAS Institute, 2009) and significant difference among the treatments was portioned by least significant difference test (LSD) at probability levels of $\mathrm{P}=$ 0.05 (Steel et al 1997).

\section{RESULTS}

1. Chemical Control of Botryodiplodia theobromae Pat., the causal pathogen of guava dieback disease

\subsection{In vitro studies}

1.1.1. Effect of the tested fungicides on mycelial linear growth $(\mathrm{mm}$.) of Botryodiplodia theobromae Pat. (Isolate code No., Q.K.4)

Data in Table (1) indicate the effect of twenty four tested fungicides at different concentrations i.e., 5, 10, 25, 50, 100, 200, 300, 400, 500 and 600 ppm., to growth PDA medium on the mycelial linear growth (mm.) of Botryodiplodia theobromae Pat. isolate code No., Q.K.4 (the most virulent isolate). The fungicide Amistar Top 325-32.5\% E.C. was highly effective in reducing the rate of mycelial growth (mm.) on PDA medium at 100 ppm., followed by Camzin 50\% W.P., Monceren 25\% W.P., Montro 30\% E.C., Topsin-M 70\% W.P., Alliette $80 \%$ W.P. and Daconil $72 \%$ S.C. at 200 ppm. conc., these set of fungicides exhibited the highest effective in reducing the rate of mycelial growth (mm.) of Botryodiplodia theobromae Pat. (isolate code No., Q.K.4.). Meanwhile, Bellis 38\% W.G. and Dithane M45 $80 \%$ W.P. were stopped the fungal linear growth $(\mathrm{mm}$.) at $300 \mathrm{ppm}$. conc. followed by, Tilt $80 \%$ W.P., Penazole 10\% E.C., Opus $12.50 \%$ S.C. at 400 ppm. conc., followed by, Master 25\% E.C. and Punch 40\% E.C., inhibited mycelial linear growth $(\mathrm{mm}$.$) at 500 \mathrm{ppm}$., these set of fungicides showed a moderate effective in reducing the rate of mycelial growth ( $\mathrm{mm}$.). 


\subsection{In vitro}

Table 1. Effect of different concentrations (p.p.m) of twenty four fungicides on mycelial linear growth (mm.) of Botryodiplodia theobromae Pat. isolate code number (Q.K.4) on PDA medium at $25 \pm 1^{\circ} \mathrm{C}$ degree.

\begin{tabular}{|c|c|c|c|c|c|c|c|c|c|c|c|c|c|}
\hline \multicolumn{3}{|c|}{ Fungicides } & \multicolumn{10}{|c|}{ Fungicides concentrations (p.p.m) } & \multirow[b]{2}{*}{ Mean } \\
\hline Trade Name & Common Name & $\begin{array}{c}0 \\
\text { (Control) }\end{array}$ & 5 & 10 & 25 & 50 & 100 & 200 & 300 & 400 & 500 & 600 & \\
\hline Alliette $80 \%$ W.P. & Fosetyl aluminium & 90.00 & 80.00 & 76.00 & 63.00 & 36.00 & 20.00 & 0.00 & 0.00 & 0.00 & 0.00 & 0.00 & 33.18 \\
\hline $\begin{array}{l}\text { Amistar Top 325- } \\
32.5 \% \text { E.C. }\end{array}$ & $\begin{array}{l}\text { Azoxystrobin- } \\
\text { Difenoconazole }\end{array}$ & 90.00 & 80.00 & 56.00 & 26.00 & 11.00 & 0.00 & 0.00 & 0.00 & 0.00 & 0.00 & 0.00 & 23.91 \\
\hline Bellis $38 \%$ W.G. & $\begin{array}{l}\text { Pyroclo- } \\
\text { strobin+Boscoild }\end{array}$ & 90.00 & 80.00 & 76.00 & 38.00 & 26.00 & 18.00 & 6.00 & 0.00 & 0.00 & 0.00 & 0.00 & 30.36 \\
\hline Camzin $50 \%$ W.P. & Carbendazim & 90.00 & 70.00 & 61.00 & 43.00 & 20.00 & 5.00 & 0.00 & 0.00 & 0.00 & 0.00 & 0.00 & 26.27 \\
\hline Copral 50\% W.P. & Copper oxychloride & 90.00 & 90.00 & 90.00 & 90.00 & 90.00 & 20.00 & 90.00 & 75.00 & 50.00 & 20.00 & 0.00 & 70.75 \\
\hline Daconil $72 \%$ S.C. & Chlorotholonil & 90.00 & 84.00 & 81.00 & 63.00 & 36.00 & 28.00 & 0.00 & 0.00 & 0.00 & 0.00 & 0.00 & 34.73 \\
\hline $\begin{array}{l}\text { Dithane M45 80\% } \\
\text { W.P. }\end{array}$ & Mancozeb & 90.00 & 84.00 & 78.00 & 68.00 & 60.00 & 42.00 & 10.00 & 0.00 & 0.00 & 0.00 & 0.00 & 39.27 \\
\hline Eminent $12.50 \%$ E.W. & Tetraconazole & 90.00 & 90.00 & 86.00 & 78.00 & 74.00 & 66.00 & 53.00 & 46.00 & 38.00 & 22.00 & 0.00 & 58.45 \\
\hline $\begin{array}{l}\text { Fungshow } 12.50 \% \\
\text { W.P. }\end{array}$ & Dinicc & 90.00 & 88.00 & 86.00 & 68.00 & 61.00 & 44.00 & 26.00 & 16.00 & 10.00 & 6.00 & 0.00 & 45.00 \\
\hline Master 25\% E.C. & Prochloraz & 90.00 & 86.00 & 83.00 & 61.00 & 43.00 & 36.00 & 14.00 & 7.00 & 4.00 & 0.00 & 0.00 & 38.54 \\
\hline Monceren 25\% W.P. & Pencycuron & 90.00 & 84.00 & 66.00 & 60.00 & 10.00 & 5.00 & 0.00 & 0.00 & 0.00 & 0.00 & 0.00 & 28.64 \\
\hline Montro 30\% E.C. & $\begin{array}{l}\text { Difenoconazole- } \\
\text { Propiconazole }\end{array}$ & 90.00 & 76.00 & 66.00 & 28.00 & 10.00 & 8.00 & 0.00 & 0.00 & 0.00 & 0.00 & 0.00 & 25.27 \\
\hline Opus $12.50 \%$ S.C. & Epoxiconazole & 90.00 & 90.00 & 90.00 & 90.00 & 90.00 & 75.00 & 40.00 & 18.00 & 0.00 & 0.00 & 0.00 & 53.00 \\
\hline Penazole $10 \%$ E.C. & Penconazole & 90.00 & 90.00 & 90.00 & 90.00 & 90.00 & 65.00 & 33.00 & 14.00 & 0.00 & 0.00 & 0.00 & 51.09 \\
\hline Punch $40 \%$ E.C. & Flusidozole & 90.00 & 90.00 & 90.00 & 90.00 & 90.00 & 90.00 & 60.00 & 38.00 & 26.00 & 0.00 & 0.00 & 60.36 \\
\hline $\begin{array}{l}\text { Ridomil Gold/Plus } \\
42.50 \% \text { W.P. }\end{array}$ & $\begin{array}{l}\text { Copper oxychlo- } \\
\text { ride+Metaloxyl M }\end{array}$ & 90.00 & 90.00 & 90.00 & 90.00 & 90.00 & 90.00 & 83.00 & 68.00 & 45.00 & 18.00 & 0.00 & 68.54 \\
\hline Rizolex T 50\% W.P. & $\begin{array}{l}\text { Thiram-Tolclofos- } \\
\text { methyl }\end{array}$ & 90.00 & 90.00 & 90.00 & 90.00 & 90.00 & 90.00 & 78.00 & 46.00 & 34.00 & 16.00 & 0.00 & 64.91 \\
\hline Rovral 50\% W.P. & Iprodione & 90.00 & 90.00 & 90.00 & 90.00 & 90.00 & 90.00 & 85.00 & 65.00 & 40.00 & 15.00 & 0.00 & 67.73 \\
\hline Score $25 \%$ E.C. & Difenoconazole & 90.00 & 90.00 & 78.00 & 65.00 & 51.00 & 48.00 & 42.00 & 26.00 & 21.00 & 6.00 & 0.00 & 47.00 \\
\hline Tecto $50 \%$ S.C. & Thiabendazole & 90.00 & 90.00 & 90.00 & 90.00 & 90.00 & 70.00 & 50.00 & 30.00 & 20.00 & 10.00 & 0.00 & 57.27 \\
\hline Thiovat Jet $80 \%$ W.G. & Sulfur & 90.00 & 90.00 & 90.00 & 90.00 & 90.00 & 90.00 & 90.00 & 80.00 & 55.00 & 30.00 & 0.00 & 72.27 \\
\hline Topsin-M 70\% W.P. & Thiophanate methyl & 90.00 & 90.00 & 83.00 & 20.00 & 14.00 & 11.00 & 0.00 & 0.00 & 0.00 & 0.00 & 0.00 & 28.00 \\
\hline Tilt 80\% W.P. & Propiconazole & 90.00 & 90.00 & 90.00 & 81.00 & 62.00 & 40.00 & 17.00 & 10.00 & 0.00 & 0.00 & 0.00 & 43.63 \\
\hline Vectra $10 \%$ S.C. & Bromuconazole & 90.00 & 90.00 & 90.00 & 90.00 & 90.00 & 80.00 & 80.00 & 50.00 & 20.00 & 5.00 & 0.00 & 62.27 \\
\hline Mean & & 90.00 & 86.33 & 81.92 & 69.25 & 58.92 & 47.12 & 35.71 & 24.54 & 15.12 & 8.42 & 0.00 & $-\cdots-\cdot-$ \\
\hline
\end{tabular}

Statistical analysis system (SAS), Duncan's studentized range (HSD) test at alpha $=0.05$

Least Significant Difference (LSD) for tested fungicides $=0.8286$

Least Significant Difference (LSD) for fungicides concentrations $=0.5609$

Least Significant Difference (LSD) for interaction between fungicides and concentrations $=2.7481$

However, the other fungicides i.e., Vectra 10\% S.C., Fung show $12.50 \%$ W.P., Score $25 \%$ E.C., Tecto 50\% S.C., Rovral 50\% W.P., Rizolex T 50\% W.P., Ridomil Gold/Plus $42.50 \%$ W.P., Copral $50 \%$ W.P., Eminent $12.50 \%$ E.W. and Thiovat Jet $80 \%$ W.G. inhibited mycelial linear growth $(\mathrm{mm}$.) at 600 ppm. and exhibited a lowest effect in reducing of mycelial linear growth (mm.). Data also, indicate that the inhibiting effect of all the previously tested fungicides were gradually increased by increasing the concentration of each fungicide and inhibited the mycelial linear growth ( $\mathrm{mm}$.) from 5 to 600 ppm., respectively. Data also, recorded the maximum linear growth of Botryodiplodia theobromae 
Pat. isolate code No., Q.K.4 was $90 \mathrm{~mm}$. in diameter on PDA medium at $0 \mathrm{ppm}$. concentration as the control treatment.

1.1.2. Effect of the tested fungicides on amount of growth (dry weight $\mathrm{mg}$.) of Botryodiplodia theobromae Pat. (Isolate code No., Q.K.4)

As for the effect of the previous twenty four tested fungicides on the total amount of growth (dry weight mg.) on Czapek's medium of Botryodiplodia theobromae Pat. isolate code No., Q.K.4 (the most virulent isolate), the Data recorded in Table (2) indicate that Amistar Top 325-32.5\% E.C. tended the same trend as with mycelial linear growth where it stopped completely the fungal growth of Botryodiplodia theobromae Pat. at 100 ppm., however, the other fungicides showed different trend followed by, Camzin 50\% W.P., Monceren 25\% W.P., Montro 30\% E.C., Topsin-M 70\% W.P., Alliette $80 \%$ W.P. and Daconil $72 \%$ S.C. at 200 ppm. conc., these set of fungicides exhibited the highest effective in reducing the total amount of growth (dry weight mg.) on Czapek's medium of Botryodiplodia theobromae Pat. isolate code No., Q.K.4. Meanwhile, Bellis 38\% W.G. and Dithane M45 80\% W.P. were stopped the amount of growth (dry weight mg.) at $300 \mathrm{ppm}$. conc. followed by, Tilt $80 \%$ W.P., Penazole 10\% E.C., Opus $12.50 \%$ S.C. at 400 ppm. conc., followed by, Master 25\% E.C. and Punch $40 \%$ E.C., inhibited amount of growth (dry weight mg.) at 500 ppm., these set of fungicides showed a moderate effective in reducing the amount of growth (dry weight mg.) of Botryodiplodia theobromae Pat. (isolate code No., Q.K.4.). However, the other fungicides i.e., Vectra $10 \%$ S.C., Fungshow 12.50\% W.P., Score 25\% E.C., Tecto 50\% S.C., Rovral 50\% W.P., Rizolex T 50\% W.P., Ridomil Gold/Plus $42.50 \%$ W.P., Copral $50 \%$ W.P., Eminent $12.50 \%$ E.W. and Thiovat Jet $80 \%$ W.G. inhibited amount of growth (dry weight mg.) at 600 ppm., and exhibited a lowest effect in reducing of amount of growth (dry weight mg.). Data also, indicate that the inhibiting effect of all the previously tested fungicides were gradually increased by increasing the concentration of each fungicide and inhibited the amount of growth (dry weight mg.) from 5 to 600 ppm., respectively.
1.2. In vivo disease control with the tested fungicides under greenhouse conditions experiment

\section{Greenhouse experiments (in vivo)}

Application of twenty four fungicides as foliar spray or soil drench to guava plants under greenhouse conditions. The efficiency of 24 fungicides (Tables 3 and 4) applied as foliage spray or soil drench the suppression for estimation their effect on guava die-back diseased trees. Data in Table (3) proved that soil drench was the higher efficient method in elimination of disease incidence followed by foliar spray. Such result was true for all fungicides. Amistar Top 325-32.5\% E.C. was the most efficient fungicide in reduce disease incidence, followed by Camzin 50\% W.P., Monceren 25\% W.P., Montro 30\% E.C., Topsin-M 70\% W.P., Alliette $80 \%$ W.P. and Daconil $72 \%$ S.C., these set of fungicides exhibited the higher efficient in reducing the disease incidence. Meanwhile, Bellis $38 \%$ W.G., Dithane M45 80\% W.P., followed by Tilt $80 \%$ W.P., Penazole 10\% E.C., Opus 12.50\% S.C., Master 25\% E.C. and Punch 40\% E.C., these set of fungicides showed a moderate efficient in reducing the disease incidence. However, other fungicides i.e., Vectra 10\% S.C., Fungshow 12.50\% W.P., Score $25 \%$ E.C., Tecto $50 \%$ S.C., Rovral 50\% W.P., Rizolex T 50\% W.P., Ridomil Gold/Plus 42.50\% W.P., Copral 50\% W.P., Eminent 12.50\% E.W. and Thiovat Jet $80 \%$ W.G. showed a least efficient in reducing the disease incidence.

Data in Table (4) proved that soil drench was the higher efficient method in elimination of disease incidence followed by foliar spray. Such result was true for all fungicides. Amistar Top 325$32.5 \%$ E.C. was the most efficient fungicide in reducing the disease incidence, followed by Camzin 50\% W.P., Monceren 25\% W.P., Montro 30\% E.C., Topsin-M 70\% W.P., Alliette $80 \%$ W.P. and Daconil $72 \%$ S.C., these set of fungicides exhibited the higher efficient in reducing disease incidence. Meanwhile, Bellis 38\% W.G., Dithane M45 80\% W.P., followed by Tilt $80 \%$ W.P., Penazole $10 \%$ E.C., Opus $12.50 \%$ S.C., Master $25 \%$ E.C. and Punch $40 \%$ E.C., these set of fungicides showed a moderate efficient in reducing the disease incidence. 
Table 2. Effect of different concentrations (p.p.m) of twenty four fungicides on the amount of mycelial growth (mg.) of Botryodiplodia theobromae Pat. isolate code (No.Q.K.4) on Czapek's growth medium at $25 \pm 1^{\circ} \mathrm{C}$ degree.

\begin{tabular}{|c|c|c|c|c|c|c|c|c|c|c|c|c|c|}
\hline \multicolumn{3}{|c|}{ Fungicides } & \multicolumn{10}{|c|}{ Fungicides concentrations (p.p.m) } & \multirow{2}{*}{ Mean } \\
\hline Trade Name & Common Name & \begin{tabular}{|c|}
0 \\
(Control) \\
\end{tabular} & 5 & 10 & 25 & 50 & 100 & 200 & 300 & 400 & 500 & 600 & \\
\hline Alliette $80 \%$ W.P. & Fosetyl alun & 260.50 & 209.80 & 152.60 & 117.50 & 96.60 & 62.80 & 0.00 & 0.00 & 0.00 & 0.00 & 0.00 & 81.80 \\
\hline $\begin{array}{c}\text { Amistar Top 325- } \\
\text { 32.5\% E.C. }\end{array}$ & $\begin{array}{l}\text { Azoxystrobin- } \\
\text { Difenoconazole }\end{array}$ & 260.50 & 140.60 & 88.60 & 38.50 & 17.40 & 0.00 & 0.00 & 0.00 & 0.00 & 0.00 & 0.00 & 49.60 \\
\hline Bellis $38 \%$ W.G. & Pyroclostrobin+Boscoild & 260.50 & 200.40 & 110.80 & 88.50 & 46.80 & 23.60 & 16.50 & 0.00 & 0.00 & 0.00 & 0.00 & 67.92 \\
\hline Camzin $50 \%$ W.P. & Carbendazim & 260.50 & 154.80 & 58.60 & 47.80 & 38.50 & 36.80 & 0.00 & 0.00 & 0.00 & 0.00 & 0.00 & 54.27 \\
\hline Copral $50 \%$ W.P. & Copper oxychloride & 260.50 & 260.50 & 260.50 & 260.50 & 230.50 & 198.60 & 169.80 & 146.80 & 59.60 & 45.60 & 0.00 & 172.08 \\
\hline Daconil $72 \%$ S.C. & Chlorotholonil & 260.50 & 231.60 & 196.80 & 146.50 & 118.80 & 88.50 & 0.00 & 0.00 & 0.00 & 0.00 & 0.00 & 94.79 \\
\hline $\begin{array}{c}\text { Dithane M45 80\% } \\
\text { W.P. }\end{array}$ & Mancozeb & 260.50 & 212.80 & 163.60 & 153.80 & 121.40 & 70.80 & 27.30 & 0.00 & 0.00 & 0.00 & 0.00 & 91.84 \\
\hline $\begin{array}{c}\text { Eminent } 12.50 \% \\
\text { E.W. }\end{array}$ & Tetraconazole & 260.50 & 254.60 & 240.80 & 212.40 & 181.60 & 146.60 & 114.60 & 106.60 & 80.50 & 66.50 & 0.00 & 151.34 \\
\hline $\begin{array}{c}\text { Fungshow } 12.50 \% \\
\text { W.P. }\end{array}$ & Diniconazole & 260.50 & 216.80 & 186.60 & 142.60 & 98.60 & 43.30 & 24.60 & 16.50 & 8.80 & 4.40 & 0.00 & 91.15 \\
\hline Master 25\% E.C. & Prochloraz & 260.50 & 215.80 & 150.60 & 115.60 & 88.60 & 53.60 & 20.00 & 16.60 & 10.40 & 0.00 & 0.00 & 84.70 \\
\hline $\begin{array}{c}\text { Monceren } 25 \% \\
\text { W.P. }\end{array}$ & Pencycuron & 260.50 & 156.80 & 78.50 & 66.40 & 53.40 & 41.80 & 0.00 & 0.00 & 0.00 & 0.00 & 0.00 & 59.76 \\
\hline Montro 30\% E.C. & $\begin{array}{l}\text { Difenoconazole- Pro- } \\
\text { piconazole }\end{array}$ & 260.50 & 228.50 & 166.60 & 146.50 & 73.80 & 48.40 & 0.00 & 0.00 & 0.00 & 0.00 & 0.00 & 84.03 \\
\hline Opus $12.50 \%$ S.C. & Epoxiconazole & 260.50 & 248.80 & 172.60 & 153.30 & 134.80 & 114.80 & 98.80 & 35.30 & 0.00 & 0.00 & 0.00 & 110.81 \\
\hline Penazole $10 \%$ E.C. & Penconazole & 260.50 & 216.80 & 193.80 & 136.80 & 100.80 & 88.80 & 60.60 & 18.50 & 0.00 & 0.00 & 0.00 & 97.87 \\
\hline Punch $40 \%$ E.C. & Flusidozole & 260.50 & 260.50 & 260.50 & 260.50 & 196.50 & 162.80 & 69.80 & 32.60 & 17.30 & 0.00 & 0.00 & 138.27 \\
\hline $\begin{array}{r}\text { Ridomi } \\
42.5\end{array}$ & $\begin{array}{l}\text { Copper o } \\
\text { ride+Mete }\end{array}$ & 260.50 & 260.50 & 260.50 & 260.50 & 260.50 & 191.80 & 168.50 & 112.60 & 52.50 & 38.00 & 0.00 & 169.63 \\
\hline T 50\% W.P. & $\begin{array}{l}\text { Thiram-Tolclofos- } \\
\text { methyl }\end{array}$ & 260.50 & 260.50 & 260.50 & 260.50 & 186.70 & 108.80 & 142.30 & 98.00 & 33.80 & 28.60 & 0.00 & 149.11 \\
\hline Rovral 50\% W.P. & Iprodione & 260.50 & 260.50 & 260.50 & 260.50 & 260.50 & 173.30 & 148.30 & 126.60 & 46.50 & 20.00 & 0.00 & 165.20 \\
\hline Score $25 \%$ E.C. & Difenoconazole & 260.50 & 200.80 & 182.60 & 121.50 & 100.60 & 90.50 & 41.20 & 18.80 & 12.80 & 8.60 & 0.00 & 94.35 \\
\hline Tecto $50 \%$ S.C. & Thiabendazole & 260.50 & 228.80 & 203.80 & 198.80 & 141.40 & 126.60 & 53.00 & 28.60 & 20.60 & 16.40 & 0.00 & 116.23 \\
\hline $\begin{array}{l}\text { Thiovat Jet } 80 \% \\
\text { W.G. }\end{array}$ & Sulfur & 260.50 & 260.50 & 260.50 & 260.50 & 260.50 & 210.80 & 186.50 & 155.60 & 118.80 & 80.60 & 0.00 & 186.80 \\
\hline Topsin-M 70\% W.P. & Thiophanate methyl & 260.50 & 252.60 & 186.80 & 156.40 & 76.50 & 56.50 & 0.00 & 0.00 & 0.00 & 0.00 & 0.00 & 89.94 \\
\hline Tilt $80 \%$ W.P. & Propiconazole & 260.50 & 214.50 & 160.50 & 120.60 & 95.60 & 86.60 & 30.80 & 16.00 & 0.00 & 0.00 & 0.00 & 89.55 \\
\hline Vectra $10 \%$ S.C. & Bromuconazole & 260.50 & 260.50 & 260.50 & 260.50 & 193.80 & 153.60 & 124.60 & 48.80 & 34.60 & 3.50 & 0.00 & 145.54 \\
\hline Mean & & 260.50 & 225.35 & 188.24 & 166.13 & 132.26 & 99.15 & 62.38 & 40.75 & 20.68 & 13.01 & 0.00 & -- \\
\hline
\end{tabular}

Statistical analysis system (SAS), Duncan's studentized range (HSD) test at alpha $=0.05$

Least Significant Difference (LSD) for tested fungicides $=1.0495$

Least Significant Difference (LSD) for fungicides concentrations $=0.7105$

Least Significant Difference (LSD) for interaction between fungicides and concentrations $=3.4807$ 

disease in Egypt

\subsection{In vivo:}

Table 3. Therapeutic effect of twenty four fungicides at recommended dose for each fungicide by two methods of application i.e. foliar spray and soil drench on disease incidence (\%) of guava die-back disease on transplants cultivar Banaty one year old, interval period of spray and soil drench 15 days for three times for each fungicide, two months after fungicides application in pot experiments under greenhouse conditions during 2015 and 2016 year.

\begin{tabular}{|c|c|c|c|c|c|c|c|c|c|c|c|c|c|c|}
\hline \multirow{4}{*}{$\begin{array}{l}\text { Tested Fungi- } \\
\text { cides }\end{array}$} & \multicolumn{14}{|c|}{ Methods of Application at recommended dose for each fungicide } \\
\hline & \multicolumn{6}{|c|}{ Foliar Spray } & \multirow{3}{*}{\begin{tabular}{|c|} 
Mean \\
$\begin{array}{c}\text { Efficacy of } \\
\text { fungicides } \%\end{array}$ \\
\end{tabular}} & \multicolumn{6}{|c|}{ Soil Drench } & \multirow{3}{*}{\begin{tabular}{|c|} 
Mean \\
$\begin{array}{c}\text { Efficacy of } \\
\text { fungicides } \%\end{array}$ \\
2015 and \\
2016 \\
\end{tabular}} \\
\hline & \multicolumn{2}{|c|}{$\begin{array}{c}\text { Disease incidence } \\
\% \text { before applica- } \\
\text { tion }\end{array}$} & \multicolumn{2}{|c|}{$\begin{array}{l}\text { Disease incidence } \\
\% 60 \text { days after } \\
\text { application }\end{array}$} & \multicolumn{2}{|c|}{$\begin{array}{c}\text { Efficacy of } \\
\text { fungicides \% }\end{array}$} & & \multicolumn{2}{|c|}{$\begin{array}{l}\text { Disease incidence } \\
\% \text { before applica- } \\
\text { tion }\end{array}$} & \multicolumn{2}{|c|}{$\begin{array}{c}\text { Disease incidence } \\
\% 60 \text { days after } \\
\text { application }\end{array}$} & \multicolumn{2}{|c|}{$\begin{array}{c}\text { Efficacy of } \\
\text { fungicides \% }\end{array}$} & \\
\hline & 2015 & 2016 & 2015 & 2016 & 2015 & 2016 & & 2015 & 2016 & 2015 & 2016 & 2015 & 2016 & \\
\hline $\begin{array}{l}\text { Alliette } 80 \% \\
\text { W.P. }\end{array}$ & 33.33 & 36.67 & 16.67 & 20.00 & 49.98 & 45.46 & 47.72 & 33.33 & 36.67 & 13.33 & 16.67 & 60.00 & 54.54 & 57.27 \\
\hline $\begin{array}{c}\text { Amistar Top } \\
325-32.5 \% \\
\text { E.C. }\end{array}$ & 33.33 & 36.67 & 6.67 & 10.00 & 80.00 & 72.73 & 76.37 & 33.33 & 36.67 & 3.33 & 6.67 & 90.00 & 81.83 & 85.92 \\
\hline $\begin{array}{l}\text { Bellis 38\% } \\
\text { W.G. }\end{array}$ & 33.33 & 36.67 & 20.00 & 23.33 & 40.00 & 36.38 & 38.19 & 33.33 & 36.67 & 16.67 & 20.00 & 49.98 & 45.46 & 47.72 \\
\hline $\begin{array}{l}\text { Camzin } 50 \% \\
\text { W.P. }\end{array}$ & 33.33 & 36.67 & 10.00 & 13.33 & 70.00 & 63.65 & 66.83 & 33.33 & 36.67 & 6.67 & 10.00 & 80.00 & 72.73 & 76.37 \\
\hline $\begin{array}{l}\text { Copral } 50 \% \\
\text { W.P. }\end{array}$ & 33.33 & 36.67 & 30.00 & 33.33 & 10.00 & 9.11 & 9.56 & 33.33 & 36.67 & 30.00 & 33.33 & 10.00 & 9.11 & 9.56 \\
\hline $\begin{array}{l}\text { Daconil } 72 \% \\
\text { S.C. }\end{array}$ & 33.33 & 36.67 & 16.67 & 20.00 & 49.98 & 45.46 & 47.72 & 33.33 & 36.67 & 16.67 & 20.00 & 49.98 & 45.46 & 47.72 \\
\hline $\begin{array}{l}\text { Dithane M45 } \\
80 \% \text { W.P. }\end{array}$ & 33.33 & 36.67 & 20.00 & 23.33 & 40.00 & 36.38 & 38.19 & 33.33 & 36.67 & 16.67 & 20.00 & 49.98 & 45.46 & 47.72 \\
\hline $\begin{array}{c}\text { Eminent } \\
12.50 \% \text { E.W. }\end{array}$ & 33.33 & 36.67 & 30.00 & 33.33 & 10.00 & 9.11 & 9.56 & 33.33 & 36.67 & 30.00 & 33.33 & 10.00 & 9.11 & 9.56 \\
\hline $\begin{array}{c}\text { Fungshow } \\
12.50 \% \text { W.P. }\end{array}$ & 33.33 & 36.67 & 26.67 & 30.00 & 19.98 & 18.19 & 19.09 & 33.33 & 36.67 & 23.33 & 26.67 & 30.00 & 27.27 & 28.64 \\
\hline $\begin{array}{l}\text { Master 25\% } \\
\text { E.C. }\end{array}$ & 33.33 & 36.67 & 23.33 & 26.67 & 30.00 & 27.27 & 28.64 & 33.33 & 36.67 & 20.00 & 23.33 & 40.00 & 36.38 & 38.19 \\
\hline $\begin{array}{c}\text { Monceren } 25 \% \\
\text { W.P. }\end{array}$ & 33.33 & 36.67 & 13.33 & 16.67 & 60.00 & 54.54 & 57.27 & 33.33 & 36.67 & 10.00 & 13.33 & 70.00 & 63.65 & 66.83 \\
\hline $\begin{array}{l}\text { Montro } 30 \% \\
\text { E.C. }\end{array}$ & 33.33 & 36.67 & 16.67 & 20.00 & 49.98 & 45.46 & 47.72 & 33.33 & 36.67 & 13.33 & 16.67 & 60.00 & 54.54 & 57.27 \\
\hline $\begin{array}{c}\text { Opus } 12.50 \% \\
\text { S.C. }\end{array}$ & 33.33 & 36.67 & 23.33 & 26.67 & 30.00 & 27.27 & 28.64 & 33.33 & 36.67 & 20.00 & 23.33 & 40.00 & 36.38 & 38.19 \\
\hline $\begin{array}{c}\text { Penazole } 10 \% \\
\text { E.C. }\end{array}$ & 33.33 & 36.67 & 20.00 & 23.33 & 40.00 & 36.38 & 38.19 & 33.33 & 36.67 & 20.00 & 23.33 & 40.00 & 36.38 & 38.19 \\
\hline $\begin{array}{l}\text { Punch } 40 \% \\
\text { E.C. }\end{array}$ & 33.33 & 36.67 & 23.33 & 26.67 & 30.00 & 27.27 & 28.64 & 33.33 & 36.67 & 23.33 & 26.67 & 30.00 & 27.27 & 28.64 \\
\hline $\begin{array}{l}\text { Ridomil } \\
\text { Gold/Plus }\end{array}$ & 33.33 & 36.67 & 30.00 & 33.33 & 10.00 & 9.11 & & 33.33 & 36.67 & 26.67 & 30.00 & 19.98 & 18.19 & 19.09 \\
\hline $\begin{array}{c}42.50 \% \text { W.P. } \\
\text { Rizolex T } 50 \% \\
\text { W.P. }\end{array}$ & 33.33 & 36.67 & 30.00 & 33.33 & 10.00 & 9.11 & 9.56 & 33.33 & 36.67 & 26.67 & 30.00 & 19.98 & 18.19 & 19.09 \\
\hline $\begin{array}{l}\text { Rovral } 50 \% \\
\text { W.P. }\end{array}$ & 33.33 & 36.67 & 26.67 & 30.00 & 19.98 & 18.19 & 19.09 & 33.33 & 36.67 & 26.67 & 30.00 & 19.98 & 18.19 & 19.09 \\
\hline $\begin{array}{l}\text { Score } 25 \% \\
\text { E.C. }\end{array}$ & 33.33 & 36.67 & 26.67 & 30.00 & 19.98 & 18.19 & 19.09 & 33.33 & 36.67 & 23.33 & 26.67 & 30.00 & 27.27 & 28.64 \\
\hline Tecto $50 \%$ S.C. & 33.33 & 36.67 & 26.67 & 30.00 & 19.98 & 18.19 & & 33.33 & 36.67 & 23.33 & 26.67 & 30.00 & 27.27 & 28.64 \\
\hline $\begin{array}{l}\text { Thiovat Jet } \\
80 \% \text { W.G. }\end{array}$ & 33.33 & 36.67 & 30.00 & 33.33 & 10.00 & 9.11 & 9.56 & 33.33 & 36.67 & 30.00 & 33.33 & 10.00 & 9.11 & 9.56 \\
\hline $\begin{array}{c}\text { Topsin-M } 70 \% \\
\text { W.P. }\end{array}$ & 33.33 & 36.67 & 16.67 & 20.00 & 49.98 & 45.46 & 47.72 & 33.33 & 36.67 & 13.33 & 16.67 & 60.00 & 54.54 & 57.27 \\
\hline Tilt 80\% W.P. & 33.33 & 36.67 & 20.00 & 23.33 & 40.00 & 36.38 & & 33.33 & 36.67 & 20.00 & 23.33 & 40.00 & 36.38 & 38.19 \\
\hline $\begin{array}{l}\text { Vectra } 10 \% \\
\text { S.C. }\end{array}$ & 33.33 & 36.67 & 23.33 & 26.67 & 30.00 & 27.27 & $\begin{array}{l}38.19 \\
28.64 \\
\end{array}$ & 33.33 & 36.67 & 26.67 & 30.00 & 19.98 & 18.19 & 19.09 \\
\hline Mean & 33.33 & 36.67 & 21.94 & 25.28 & 34.16 & 31.07 & ------- & 33.33 & 36.67 & 20.00 & 23.33 & 39.99 & 36.37 & ------- \\
\hline
\end{tabular}

Statistical analysis system (SAS), Duncan's studentized range (HSD) test at alpha $=0.05$

Least Significant Difference (LSD) for methods of application $=0.3041$

Least Significant Difference (LSD) for tested fungicides $=1.0535$ 
Table 4. Therapeutic effect of twenty four fungicides at recommended dose for each fungicide by two methods of application i.e. foliar spray and soil drench on disease severity (\%) of guava die-back disease on transplants cultivar Banaty one year old, interval period of spray and soil drench 15 days for three times for each fungicide, two months after fungicides application in pot experiments under greenhouse conditions during 2015 and 2016 year.

\begin{tabular}{|c|c|c|c|c|c|c|c|c|c|c|c|c|c|c|}
\hline \multirow{4}{*}{$\begin{array}{l}\text { Tested } \\
\text { Fungicides }\end{array}$} & \multicolumn{14}{|c|}{ Methods of Application at recommended dose for each fungicide } \\
\hline & \multicolumn{6}{|c|}{ Foliar Spray } & Mean & \multicolumn{6}{|c|}{ Soil Drench } & \multirow{3}{*}{$\begin{array}{c}\text { Mean } \\
\begin{array}{c}\text { Efficacy of } \\
\text { fungicides } \\
\%\end{array} \\
\begin{array}{c}2015 \text { and } \\
2016\end{array}\end{array}$} \\
\hline & \multicolumn{2}{|c|}{$\begin{array}{c}\begin{array}{c}\text { Disease severity } \\
\% \text { before appli- } \\
\text { cation }\end{array} \\
\end{array}$} & \multicolumn{2}{|c|}{$\begin{array}{c}\text { Disease severity } \\
\% 60 \text { days after } \\
\text { application }\end{array}$} & \multicolumn{2}{|c|}{$\begin{array}{c}\text { Efficacy of } \\
\text { fungicides \% }\end{array}$} & \multirow{2}{*}{$\begin{array}{c}\begin{array}{c}\text { Efficacy of } \\
\text { fungicides } \\
\%\end{array} \\
2015 \text { and } \\
2016 \\
\end{array}$} & \multicolumn{2}{|c|}{$\begin{array}{c}\text { Disease severity } \\
\% \text { before appli- } \\
\text { cation }\end{array}$} & \multicolumn{2}{|c|}{$\begin{array}{c}\text { Disease severity } \\
\% 60 \text { days after } \\
\text { application }\end{array}$} & \multicolumn{2}{|c|}{$\begin{array}{c}\text { Efficacy of } \\
\text { fungicides } \%\end{array}$} & \\
\hline & 2015 & 2016 & 2015 & 2016 & 2015 & 2016 & & 2015 & 2016 & 2015 & 2016 & 2015 & 2016 & \\
\hline $\begin{array}{l}\text { Alliette } 80 \% \\
\text { W.P. }\end{array}$ & 53.33 & 56.67 & 13.33 & 9.33 & 75.00 & 83.54 & 79.27 & 53.33 & 56.67 & 13.33 & 14.67 & 75.00 & 74.11 & 74.56 \\
\hline $\begin{array}{c}\text { Amistar Top } \\
325-32.5 \% \\
\text { E.C. }\end{array}$ & 53.33 & 56.67 & 3.33 & 4.67 & 93.75 & 91.76 & 92.76 & 53.33 & 56.67 & 5.33 & 6.67 & 90.00 & 88.23 & 89.12 \\
\hline $\begin{array}{l}\text { Bellis } 38 \% \\
\text { W.G. }\end{array}$ & 53.33 & 56.67 & 18.67 & 16.67 & 65.00 & 70.58 & 67.79 & 53.33 & 56.67 & 16.67 & 18.67 & 68.74 & 67.05 & 67.90 \\
\hline $\begin{array}{c}\text { Camzin } 50 \% \\
\text { W.P. }\end{array}$ & 53.33 & 56.67 & 4.67 & 5.33 & 91.24 & 90.59 & 90.92 & 53.33 & 56.67 & 6.67 & 8.00 & 87.49 & 85.88 & 86.69 \\
\hline $\begin{array}{l}\text { Copral } 50 \% \\
\text { W.P. }\end{array}$ & 53.33 & 56.67 & 50.00 & 50.67 & 6.24 & 10.59 & 8.42 & 53.33 & 56.67 & 43.33 & 42.67 & 18.75 & 24.70 & 21.73 \\
\hline $\begin{array}{c}\text { Daconil } 72 \% \\
\text { S.C. }\end{array}$ & 53.33 & 56.67 & 15.33 & 14.67 & 71.25 & 74.11 & 72.68 & 53.33 & 56.67 & 15.33 & 16.67 & 71.25 & 70.58 & 70.92 \\
\hline $\begin{array}{c}\text { Dithane M45 } \\
80 \% \text { W.P. }\end{array}$ & 53.33 & 56.67 & 16.67 & 18.67 & 68.74 & 67.05 & 67.90 & 53.33 & 56.67 & 18.67 & 20.00 & 65.00 & 64.71 & 64.86 \\
\hline $\begin{array}{c}\text { Eminent } \\
12.50 \% \text { E.W. }\end{array}$ & 53.33 & 56.67 & 51.33 & 52.67 & 3.75 & 7.06 & 5.41 & 53.33 & 56.67 & 45.33 & 44.00 & 15.00 & 22.36 & 18.68 \\
\hline $\begin{array}{c}\text { Fungshow } \\
12.50 \% \text { W.P. }\end{array}$ & 53.33 & 56.67 & 37.33 & 35.33 & 30.00 & 37.65 & 33.83 & 53.33 & 56.67 & 29.33 & 31.33 & 45.00 & 44.71 & 44.86 \\
\hline $\begin{array}{l}\text { Master 25\% } \\
\text { E.C. }\end{array}$ & 53.33 & 56.67 & 25.33 & 28.67 & 52.20 & 49.41 & 50.81 & 53.33 & 56.67 & 23.33 & 26.67 & 56.25 & 52.94 & 54.60 \\
\hline $\begin{array}{l}\text { Monceren } \\
25 \% \text { W.P. }\end{array}$ & 53.33 & 56.67 & 6.67 & 6.67 & 87.49 & 88.23 & 87.86 & 53.33 & 56.67 & 7.33 & 9.33 & 86.25 & 83.54 & 84.90 \\
\hline $\begin{array}{c}\text { Montro } 30 \% \\
\text { E.C. }\end{array}$ & 53.33 & 56.67 & 9.33 & 8.67 & 82.50 & 84.70 & 83.60 & 53.33 & 56.67 & 8.67 & 10.67 & 83.74 & 81.17 & 82.46 \\
\hline $\begin{array}{c}\text { Opus } 12.50 \% \\
\text { S.C. }\end{array}$ & 53.33 & 56.67 & 23.33 & 26.67 & 56.25 & 52.94 & 54.60 & 53.33 & 56.67 & 22.67 & 24.67 & 57.49 & 56.47 & 56.98 \\
\hline $\begin{array}{c}\text { Penazole } 10 \% \\
\text { E.C. }\end{array}$ & 53.33 & 56.67 & 21.33 & 23.33 & 60.00 & 58.83 & 59.42 & 53.33 & 56.67 & 21.33 & 23.33 & 60.00 & 58.33 & 59.17 \\
\hline $\begin{array}{c}\text { Punch } 40 \% \\
\text { E.C. }\end{array}$ & 53.33 & 56.67 & 29.33 & 31.33 & 45.00 & 44.71 & 44.86 & 53.33 & 56.67 & 25.33 & 28.67 & 52.20 & 49.41 & 50.81 \\
\hline $\begin{array}{c}\text { Gold/Plus } \\
42.50 \% \text { W.P. }\end{array}$ & 53.33 & 56.67 & 49.33 & 48.67 & 7.50 & 14.12 & 10.81 & 53.33 & 56.67 & 41.33 & 40.67 & 22.50 & 28.23 & 25.37 \\
\hline $\begin{array}{c}\text { Rizolex T } 50 \% \\
\text { W.P. }\end{array}$ & 53.33 & 56.67 & 47.33 & 45.33 & 11.25 & 20.00 & 15.63 & 53.33 & 56.67 & 39.33 & 40.67 & 26.25 & 28.23 & 27.24 \\
\hline $\begin{array}{l}\text { Rovral } 50 \% \\
\text { W.P. }\end{array}$ & 53.33 & 56.67 & 45.33 & 43.33 & 15.00 & 23.54 & 19.27 & 53.33 & 56.67 & 37.33 & 36.67 & 30.00 & 35.29 & 32.65 \\
\hline $\begin{array}{l}\text { Score } 25 \% \\
\text { E.C. }\end{array}$ & 53.33 & 56.67 & 39.33 & 37.33 & 26.25 & 34.12 & 30.19 & 53.33 & 56.67 & 31.33 & 32.67 & 41.25 & 42.35 & 41.80 \\
\hline $\begin{array}{l}\text { Tecto } 50 \% \\
\text { S.C. }\end{array}$ & 53.33 & 56.67 & 41.33 & 40.67 & 22.50 & 28.23 & 25.37 & 53.33 & 56.67 & 33.33 & 34.67 & 37.50 & 38.82 & 38.16 \\
\hline $\begin{array}{l}\text { Thiovat Jet } \\
80 \% \text { W.G. }\end{array}$ & 53.33 & 56.67 & 52.00 & 54.00 & 2.49 & 4.71 & 3.60 & 53.33 & 56.67 & 47.33 & 45.33 & 11.25 & 20.00 & 15.63 \\
\hline $\begin{array}{c}\text { Topsin-M } 70 \% \\
\text { W.P. }\end{array}$ & 53.33 & 56.67 & 11.33 & 10.67 & 78.75 & 81.17 & 79.96 & 53.33 & 56.67 & 11.33 & 12.67 & 78.75 & 77.64 & 78.20 \\
\hline Tilt $80 \%$ W.P. & 53.33 & 56.67 & 19.33 & 21.33 & 63.75 & 62.36 & 63.06 & 53.33 & 56.67 & 19.33 & 21.33 & 63.75 & 62.36 & 63.06 \\
\hline $\begin{array}{l}\text { Vectra } 10 \% \\
\text { S.C. }\end{array}$ & 53.33 & 56.67 & 33.33 & 32.67 & 37.50 & 42.35 & 39.93 & 53.33 & 56.67 & 27.33 & 30.67 & 48.75 & 45.88 & 47.32 \\
\hline Mean & 53.33 & 56.67 & 27.69 & 27.81 & 48.06 & 50.93 & 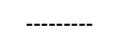 & 53.33 & 56.67 & 24.61 & 25.89 & 53.84 & 54.29 & 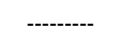 \\
\hline
\end{tabular}

Statistical analysis system (SAS), Duncan's studentized range (HSD) test at alpha $=0.05$

Least Significant Difference (LSD) for methods of application $=0.0712$

Least Significant Difference (LSD) for tested fungicides $=0.2467$ 
However, the other fungicides i.e., Vectra $10 \%$ S.C., Fungshow $12.50 \%$ W.P., Score $25 \%$ E.C., Tecto 50\% S.C., Rovral 50\% W.P., Rizolex T 50\% W.P., Ridomil Gold/Plus 42.50\% W.P., Copral 50\% W.P., Eminent $12.50 \%$ E.W. and Thiovat Jet $80 \%$ W.G. showed a least efficient in reducing disease incidence of Botryodiplodia theobromae Pat. (isolate code No., Q.K.4.).

\section{Cultivar reaction}

Information about cultivar reaction of guava transplants against Botryodiplodia theobromae is still scanty, ten coded isolates of Botryodiplodia theobromae Pat., i.e., B.W.1, A.B.2, D.S.3, Q.K. 4, A.A.5, B.N.6, K.Q.7, Q.S.8, D.B.9 and K.D.10., based on molecular diversity characters obtained from ten different geographic locations of five governorates in Egypt were tested for their pathogenic capabilities on four different guava cultivars i.e., Banaty, Malisy Ahmr, El-Mobaker and Gizy Ahmr during periods after inoculation (15, 30, 45 and 60 days) in pots experiments under greenhouse conditions. Data in Tables (5, 6, 7 and 8) showed that, the reactions of Banaty, Malisy Ahmr, ElMobaker and Gizy Ahmr cultivars to such isolates. It is cleared that all the ten isolates of Botryodiplodia theobromae Pat. according to their capability to infection of all different four guava cultivars homogenous transplant one year old were pathogenic with 15, 30, 45 and 60 days after inoculation with different degrees.

Data also, indicated that all four guava cultivar reactions were differed from cultivar to another, where Banaty was the most susceptible cultivar to the all tested Botryodiplodia theobromae isolates, while Malisy Ahmr and El-Mobaker were moderate susceptible cultivars. Meanwhile, Gizy Ahmr was the lowest susceptible cultivar. Also, the disease incidence and disease severity of the tested isolates were increased by increasing periods after inoculation (15, 30, 45 and 60 days).

Table 5. Cultivar reaction of guava transplants (Banaty c.v. 30 transplants for each treatment) to infection with ten isolates of Botryodiplodia theobromae Pat. at 15, 30, 45 and 60 days after inoculation under greenhouse conditions during 2016 year.

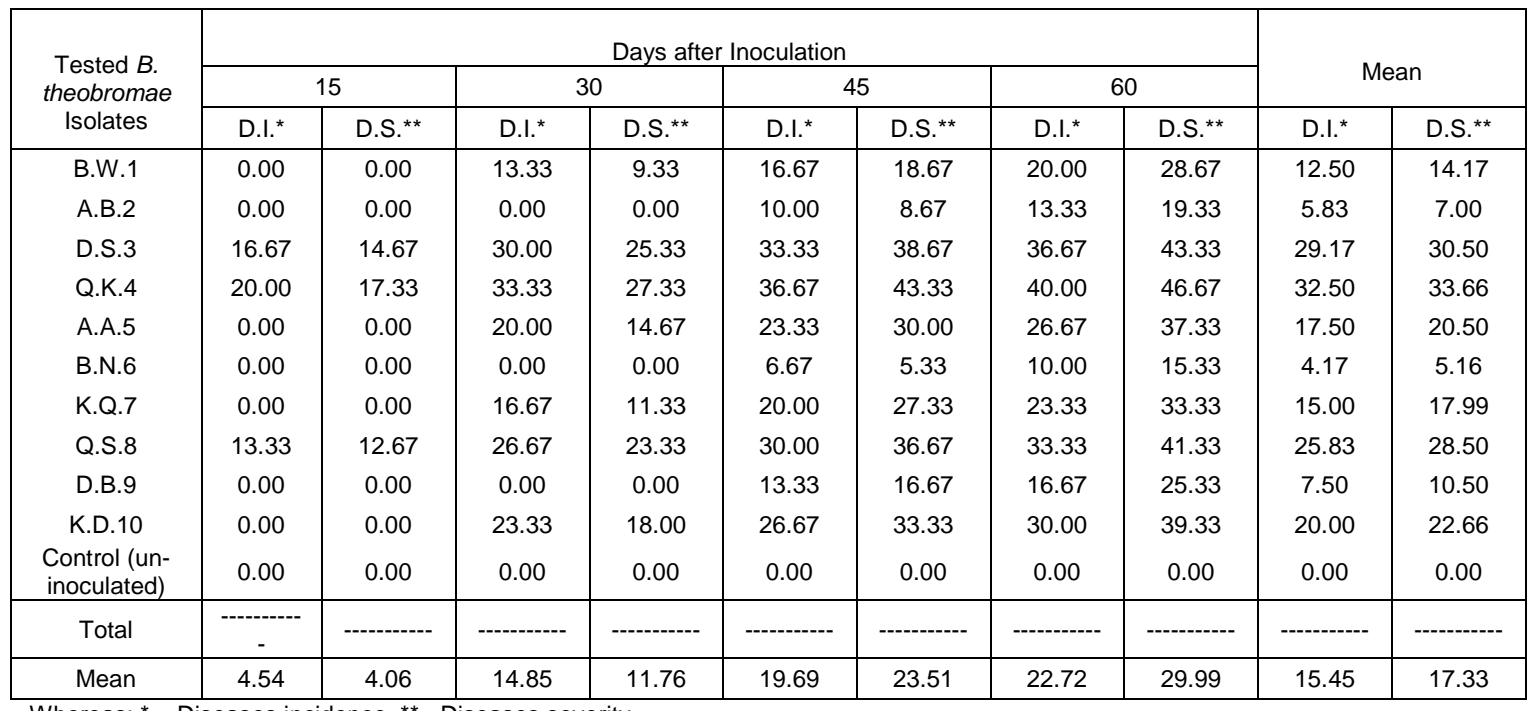

Whereas: ${ }^{*}=$ Diseases incidence,,$^{* *}=$ Diseases severity

Statistical analysis system (SAS), Duncan's studentized range (HSD) test at alpha $=0.05$

Least Significant Difference (LSD) for tested $B$. theobromae isolates as percentages for disease incidence $=1.3444$

Least Significant Difference (LSD) for days after inoculation $(15,30,45$ and 60 ) as percentages for disease incidence $=0.4924$

Least Significant Difference (LSD) for days after inoculation as percentages for disease incidence after 15 days of inoculation=1.3084 Least Significant Difference (LSD) for days after inoculation as percentages for disease incidence after 30 days of inoculation $=2.1447$ Least Significant Difference (LSD) for days after inoculation as percentages for disease incidence after 45 days of inoculation $=2.0812$ Least Significant Difference (LSD) for days after inoculation as percentages for disease incidence after 60 days of inoculation=2.1973 Least Significant Difference (LSD) for tested $B$. theobromae isolates as percentages for disease severity $=0.2712$

Least Significant Difference (LSD) for days after inoculation (15, 30, 45 and 60) as percentages for disease severity $=0.0988$

Least Significant Difference (LSD) for days after inoculation as percentages for disease severity after 15 days of inoculation $=0.1663$ Least Significant Difference (LSD) for days after inoculation as percentages for disease severity after 30 days of inoculation $=0.212$

Least Significant Difference (LSD) for days after inoculation as percentages for disease severity after 45 days of inoculation= 0.3035 Least Significant Difference (LSD) for days after inoculation as percentages for disease severity after 60 days of inoculation=0.6791 
Table 6. Cultivar reaction of guava transplants (Malisy Ahmr c.v. 30 transplants for each treatment) to infection with ten isolates of Botryodiplodia theobromae Pat.at 15, 30, 45 and 60 days after inoculation under greenhouse conditions during 2016 year.

\begin{tabular}{|c|c|c|c|c|c|c|c|c|c|c|}
\hline \multirow{3}{*}{ Tested B. theobromae Isolates } & \multicolumn{8}{|c|}{ Days after Inoculation } & \multirow{2}{*}{\multicolumn{2}{|c|}{ Mean }} \\
\hline & \multicolumn{2}{|c|}{15} & \multicolumn{2}{|c|}{30} & \multicolumn{2}{|c|}{45} & \multicolumn{2}{|c|}{60} & & \\
\hline & D.I. ${ }^{*}$ & D.S.** & D.I. ${ }^{*}$ & D.S. $^{* *}$ & D.I. ${ }^{*}$ & D.S. $^{* *}$ & D.I.* & D.S. ${ }^{\star \star}$ & D.I. ${ }^{*}$ & D.S.** \\
\hline B.W.1 & 0.00 & 0.00 & 10.00 & 7.33 & 13.33 & 15.33 & 16.67 & 25.33 & 10.17 & 11.99 \\
\hline A.B.2 & 0.00 & 0.00 & 0.00 & 0.00 & 6.67 & 7.33 & 10.00 & 17.33 & 4.17 & 6.16 \\
\hline D.S.3 & 13.33 & 11.33 & 26.67 & 21.33 & 30.00 & 33.33 & 33.33 & 36.67 & 25.83 & 25.66 \\
\hline Q.K.4 & 16.67 & 15.33 & 30.00 & 24.67 & 33.33 & 38.67 & 36.67 & 41.33 & 29.17 & 30.00 \\
\hline A.A.5 & 0.00 & 0.00 & 16.67 & 12.67 & 20.00 & 25.33 & 23.33 & 31.33 & 15.00 & 17.33 \\
\hline B.N.6 & 0.00 & 0.00 & 0.00 & 0.00 & 3.33 & 4.67 & 6.67 & 13.33 & 2.50 & 4.50 \\
\hline K.Q.7 & 0.00 & 0.00 & 13.33 & 10.67 & 16.67 & 22.67 & 20.00 & 30.67 & 12.67 & 16.00 \\
\hline Q.S.8 & 10.00 & 10.67 & 23.33 & 20.67 & 26.67 & 33.33 & 30.00 & 36.67 & 22.67 & 25.34 \\
\hline D.B.9 & 0.00 & 0.00 & 0.00 & 0.00 & 10.00 & 13.33 & 13.33 & 19.33 & 5.83 & 8.16 \\
\hline K.D.10 & 0.00 & 0.00 & 20.00 & 17.33 & 23.33 & 30.67 & 26.67 & 34.67 & 17.50 & 20.67 \\
\hline Control (un-inoculated) & 0.00 & 0.00 & 0.00 & 0.00 & 0.00 & 0.00 & 0.00 & 0.00 & 0.00 & 0.00 \\
\hline Total & ----- & ------- & $\begin{array}{l}----- \\
\end{array}$ & ------- & $\begin{array}{l}---- \\
\end{array}$ & ------- & ----- & ------- & ----- & ------- \\
\hline Mean & 3.64 & 3.39 & 12.79 & 10.42 & 16.67 & 20.42 & 19.82 & 26.06 & 13.23 & 15.07 \\
\hline
\end{tabular}

Whereas: ${ }^{*}=$ Diseases incidence ${ }^{* *}=$ Diseases severity

Statistical analysis system (SAS), Duncan's studentized range (HSD) test at alpha $=0.05$

Least Significant Difference (LSD) for tested $B$. theobromae isolates as percentages for disease incidence $=1.3945$

Least Significant Difference (LSD) for days after inoculation (15, 30, 45 and 60) as percentages for disease incidence $=0.4301$

Least Significant Difference (LSD) for days after inoculation as percentages for disease incidence after 15 days of inoculation=1.0605

Least Significant Difference (LSD) for days after inoculation as percentages for disease incidence after 30 days of inoculation=2.0034

Least Significant Difference (LSD) for days after inoculation as percentages for disease incidence after 45 days of inoculation= 2.2173

Least Significant Difference (LSD) for days after inoculation as percentages for disease incidence after 60 days of inoculation=2.0033 Least Significant Difference (LSD) for tested $B$. theobromae isolates as percentages for disease severity $=0.279$

Least Significant Difference (LSD) for days after inoculation (15, 30, 45 and 60) as percentages for disease severity= 0.0915

Least Significant Difference (LSD) for days after inoculation as percentages for disease severity after 15 days of inoculation= 0.1414

Least Significant Difference (LSD) for days after inoculation as percentages for disease severity after 30 days of inoculation=0.2057 Least Significant Difference (LSD) for days after inoculation as percentages for disease severity after 45 days of inoculation= 0.2282 Least Significant Difference (LSD) for days after inoculation as percentages for disease severity after 60 days of inoculation $=0.6938$

Table 7. Cultivar reaction of guava transplants (El-Mobaker c.v. 30 transplants for each treatment) to infect with ten isolates of Botryodiplodia theobromae Pat. at 15,30, 45 and 60 days after inoculation under greenhouse conditions during 2016 year.

\begin{tabular}{|c|c|c|c|c|c|c|c|c|c|c|}
\hline \multirow[t]{3}{*}{ Tested $B$. theobromae Isolates } & \multicolumn{8}{|c|}{ Days after Inoculation } & \multirow{2}{*}{\multicolumn{2}{|c|}{ Mean }} \\
\hline & \multicolumn{2}{|c|}{15} & \multicolumn{2}{|c|}{30} & \multicolumn{2}{|c|}{45} & \multicolumn{2}{|c|}{60} & & \\
\hline & D.I.* & D.S. ${ }^{*}$ & D.I.* & D.S. ** & D.I.* & D.S. ${ }^{*}$ & D.I.* & D.S. ${ }^{\star *}$ & D.I. & D.S. \\
\hline B.W.1 & 0.00 & 0.00 & 6.67 & 5.33 & 10.00 & 12.67 & 13.33 & 22.67 & 7.50 & 10.17 \\
\hline A.B.2 & 0.00 & 0.00 & 0.00 & 0.00 & 3.33 & 5.33 & 6.67 & 11.33 & 2.50 & 4.16 \\
\hline D.S.3 & 10.00 & 9.33 & 23.33 & 18.67 & 26.67 & 30.67 & 30.00 & 33.33 & 22.50 & 23.00 \\
\hline Q.K.4 & 13.33 & 14.67 & 26.67 & 21.33 & 30.00 & 35.33 & 33.33 & 37.33 & 25.83 & 27.16 \\
\hline A.A.5 & 0.00 & 0.00 & 13.33 & 11.33 & 16.67 & 21.33 & 20.00 & 29.33 & 12.50 & 15.49 \\
\hline B.N.6 & 0.00 & 0.00 & 0.00 & 0.00 & 0.00 & 0.00 & 3.33 & 8.67 & 0.83 & 2.17 \\
\hline K.Q.7 & 0.00 & 0.00 & 10.00 & 8.67 & 13.33 & 14.67 & 16.67 & 27.33 & 10.00 & 12.67 \\
\hline Q.S.8 & 6.67 & 9.33 & 20.00 & 17.33 & 23.33 & 28.67 & 26.67 & 31.33 & 19.17 & 21.66 \\
\hline D.B.9 & 0.00 & 0.00 & 0.00 & 0.00 & 6.67 & 11.33 & 10.00 & 16.67 & 4.17 & 7.00 \\
\hline K.D.10 & 0.00 & 0.00 & 16.67 & 14.67 & 20.00 & 26.67 & 23.33 & 29.33 & 15.00 & 17.67 \\
\hline Control (un-inoculated) & 0.00 & 0.00 & 0.00 & 0.00 & 0.00 & 0.00 & 0.00 & 0.00 & 0.00 & 0.00 \\
\hline Total & 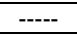 & ------- & $-\cdots$ & ------ & 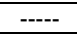 & ------- & $-\cdots$ & ------- & $\begin{array}{ll}---- \\
\end{array}$ & ------ \\
\hline Mean & 2.73 & 3.03 & 10.61 & 8.85 & 13.64 & 16.97 & 16.67 & 22.48 & 10.90 & 12.83 \\
\hline
\end{tabular}

Whereas: ${ }^{*}=$ Diseases incidence,${ }^{*}=$ Diseases severity

Statistical analysis system (SAS), Duncan's studentized range (HSD) test at alpha $=0.05$

Least Significant Difference (LSD) for tested $B$. theobromae isolates as percentages for disease incidence $=1.3544$

Least Significant Difference (LSD) for days after inoculation $(15,30,45$ and 60) as percentages for disease incidence $=0.4156$

Least Significant Difference (LSD) for days after inoculation as percentages for disease incidence after 15 days of inoculation=1.0605

Least Significant Difference (LSD) for days after inoculation as percentages for disease incidence after 30 days of inoculation=1.8987 Least Significant Difference (LSD) for days after inoculation as percentages for disease incidence after 45 days of inoculation=2.0148 Least Significant Difference (LSD) for days after inoculation as percentages for disease incidence after 60 days of inoculation=2.1022 Least Significant Difference (LSD) for tested $B$. theobromae isolates as percentages for disease severity $=0.1819$

Least Significant Difference (LSD) for days after inoculation (15, 30, 45 and 60) as percentages for disease severity= 0.0559

Least Significant Difference (LSD) for days after inoculation as percentages for disease severity after 15 days of inoculation $=0.1007$ Least Significant Difference (LSD) for days after inoculation as percentages for disease severity after 30 days of inoculation= 0.199 Least Significant Difference (LSD) for days after inoculation as percentages for disease severity after 45 days of inoculation $=0.2396$ Least Significant Difference (LSD) for days after inoculation as percentages for disease severity after 60 days of inoculation $=0.3625$ 

disease in Egypt

Table 8. Cultivar reaction of guava transplants (Gizy Ahmr c.v. 30 transplants for each treatment) to infect with ten isolates of Botryodiplodia theobromae Pat.at 15, 30, 45 and 60 days after inoculation under greenhouse conditions during 2016 year.

\begin{tabular}{|c|c|c|c|c|c|c|c|c|c|c|}
\hline \multirow{3}{*}{$\begin{array}{c}\text { Tested B. theobromae } \\
\text { Isolates }\end{array}$} & \multicolumn{8}{|c|}{ Days after Inoculation } & \multirow{2}{*}{\multicolumn{2}{|c|}{ Mean }} \\
\hline & \multicolumn{2}{|c|}{15} & \multicolumn{2}{|c|}{30} & \multicolumn{2}{|c|}{45} & \multicolumn{2}{|c|}{60} & & \\
\hline & D.I.* & D.S.** & D.I.* & D.S. ${ }^{* *}$ & D.I.. & D.S. ${ }^{* *}$ & D.I.* & D.S. $^{* *}$ & D.I.* & D.S.** \\
\hline B.W.1 & 0.00 & 0.00 & 3.33 & 4.67 & 6.67 & 10.67 & 10.00 & 18.67 & 5.00 & 8.50 \\
\hline A.B.2 & 0.00 & 0.00 & 0.00 & 0.00 & 3.33 & 4.67 & 3.33 & 8.67 & 1.66 & 3.33 \\
\hline D.S.3 & 6.67 & 7.33 & 20.00 & 15.33 & 23.33 & 27.33 & 26.67 & 31.33 & 19.17 & 20.33 \\
\hline Q.K.4 & 10.00 & 12.67 & 23.33 & 17.33 & 26.67 & 31.33 & 30.00 & 33.33 & 22.50 & 23.66 \\
\hline A.A. 5 & 0.00 & 0.00 & 10.00 & 9.33 & 13.33 & 18.67 & 16.67 & 27.33 & 10.00 & 13.83 \\
\hline B.N.6 & 0.00 & 0.00 & 0.00 & 0.00 & 0.00 & 0.00 & 3.33 & 6.67 & 0.83 & 1.67 \\
\hline K.Q.7 & 0.00 & 0.00 & 6.67 & 6.67 & 10.00 & 11.33 & 13.33 & 23.33 & 7.50 & 10.33 \\
\hline Q.S.8 & 3.33 & 6.67 & 16.67 & 15.33 & 20.00 & 23.33 & 23.33 & 26.67 & 15.83 & 18.00 \\
\hline D.B.9 & 0.00 & 0.00 & 0.00 & 0.00 & 3.33 & 8.67 & 6.67 & 13.33 & 2.50 & 5.50 \\
\hline K.D.10 & 0.00 & 0.00 & 13.33 & 11.33 & 16.67 & 23.33 & 20.00 & 25.33 & 12.50 & 15.00 \\
\hline Control (un-inoculated) & 0.00 & 0.00 & 0.00 & 0.00 & 0.00 & 0.00 & 0.00 & 0.00 & 0.00 & 0.00 \\
\hline Total & --------- & ---------- & --------- & --------- & ---------- & ---------- & ---------- & ---------- & --------- & ---------- \\
\hline Mean & 1.82 & 2.42 & 8.48 & 7.27 & 11.21 & 14.48 & 13.94 & 19.51 & 8.86 & 10.92 \\
\hline
\end{tabular}

Whereas: * $=$ Diseases incidence,${ }^{* *}=$ Diseases severity

Statistical analysis system (SAS), Duncan's studentized range (HSD) test at alpha $=0.05$

Least Significant Difference (LSD) for tested B. theobromae isolates as percentages for disease incidence $=1.3501$

Least Significant Difference (LSD) for days after inoculation (15, 30, 45 and 60) as percentages for disease incidence $=0.4009$

Least Significant Difference (LSD) for days after inoculation as percentages for disease incidence after 15 days of inoculation= 0.9719 Least Significant Difference (LSD) for days after inoculation as percentages for disease incidence after 30 days of inoculation=1.8507 Least Significant Difference (LSD) for days after inoculation as percentages for disease incidence after 45 days of inoculation $=2.003$ Least Significant Difference (LSD) for days after inoculation as percentages for disease incidence after 60 days of inoculation $=2.0914$ Least Significant Difference (LSD) for tested $B$. theobromae isolates as percentages for disease severity $=0.1114$

Least Significant Difference (LSD) for days after inoculation (15, 30, 45 and 60) as percentages for disease severity $=0.0518$

Least Significant Difference (LSD) for days after inoculation as percentages for disease severity after 15 days of inoculation $=0.0736$ Least Significant Difference (LSD) for days after inoculation as percentages for disease severity after 30 days of inoculation=0.1328 Least Significant Difference (LSD) for days after inoculation as percentages for disease severity after 45 days of inoculation= 0.157 Least Significant Difference (LSD) for days after inoculation as percentages for disease severity after 60 days of inoculation= 0.3055

\section{DISCUSSION}

Guava (Pisidium guajava L.,) is considered one of the most important popular fruit crops to the Egyptian people. Guava die-back disease is an important and economic serious problem causing severe guava losses in both nurseries and orchards in Egypt (Baiuomy et al 2003 and Kamhawy, 2011) caused by Botryodiplodia theobromae Pat. (Lasiodiplodia theobromae Pat.). Several investigators have been recorded that Botryodiplodia theobromae Pat. is a soil borne phytopathogen fungus and attack guava trees (Pisidium guajava L.) and wide spread in the world (Rana, 1981, Adisa, 1985, Majumdar and Pathak, 1997, Junqueira et al 2001, Cardoso et al 2002, Pandit and Samajpati, 2002, Baiuomy, et al 2003, Pandit and Samajpati, 2005, Mishra and Sitansu, Pan, 2007, Bokhari et al 2008, Nunes et al 2008, Mishra et al 2009, Sitansu, Pan and Mishra, 2010, Kamhawy, 2011 and Asma Safdar, et al 2015).
Although the recent strategy of control plant diseases is depend upon minimizing of fungicidal utilization to avoid environmental pollution and keep human health, fungicides will be one of Integrated Pest Management (IPM) weapons, fungicides are still one of the most important means to control the causal pathogens of different diseases. The chemical control of guava die-back disease caused by Botryodiplodia theobromae Pat. by fungicides was concerned for a long time accounting for the great importance of this disease and high loss in yield in contaminated soils in different lands. The evaluation of twenty four systemic and non-systemic fungicides was tested in in vitro and in in vivo to evaluate their effect on the fungal growth, disease incidence and disease severity, respectively.

Data obtained showed that increasing fungicidal concentrations decreased the both of linear growth and amount growth of the tested Botryodiplodia theobromae isolate code No. Q.K.4. Although, effect of fungicides was differed, inhibition 
of the linear growth and amount growth was at different concentrations of the tested fungicides. Amistar Top 325-32.5\% E.C. gave the highest decrease of linear growth and amount of growth, followed by Camzin 50\% W.P., Monceren 25\% W.P., Montro 30\% E.C., Topsin-M 70\% W.P., Alliette $80 \%$ W.P. and Daconil $72 \%$ S.C., these set of fungicides exhibited the highest effective in reducing the rate of mycelial growth and amount of growth. Meanwhile, Bellis 38\% W.G., followed by Dithane M45 80\% W.P., Tilt 80\% W.P., Penazole 10\% E.C., Opus $12.50 \%$ S.C., Master $25 \%$ E.C. and Punch $40 \%$ E.C., these set of fungicides showed a moderate effective in reducing the rate of linear growth and amount of growth. However, the other fungicides i.e., Vectra 10\% S.C., Fungshow $12.50 \%$ W.P., Score 25\% E.C., Tecto 50\% S.C., Rovral 50\% W.P., Rizolex T 50\% W.P., Ridomil Gold/Plus 42.50\% W.P., Copral 50\% W.P., Eminent $12.50 \%$ E.W. and Thiovat Jet $80 \%$ W.G. exhibited a lowest effect in reducing of linear growth and amount growth of Botryodiplodia theobromae Pat. isolate code No., Q.K.4. The former results were in accordance relatively with $\mathbf{L i}$, Hong-Ye, 1995, Baiuomy et al 2003, Abd El-Aziz et al 2010, Korra et al 2014 and Safdar, Asma et al 2015.

As such fungicides were applied under greenhouse conditions in two different trials, i.e. foliar spray and soil drench. The former method (soil drench) resulted in the highest efficiency on disease control. This result was related to the nature as soil borne fungus Botryodiplodia theobromae in its colonization to soil and high persistence as fruiting bodies (pycnidia) in it. The differences of fungicides efficiency may be due to the differences of their active ingredient and chemical groups.

Amistar Top 325-32.5\% E.C. was the most efficient fungicide in reduce disease incidence and disease severity of Botryodiplodia theobromae Pat. (isolate code No., Q.K.4.), followed by Camzin 50\% W.P., Monceren 25\% W.P., Montro 30\% E.C., Topsin-M 70\% W.P., Alliette $80 \%$ W.P. and Daconil $72 \%$ S.C., Bellis $38 \%$ W.G., Dithane M45 $80 \%$ W.P., followed by Tilt $80 \%$ W.P., Penazole $10 \%$ E.C., Opus $12.50 \%$ S.C., Master 25\% E.C., Punch $40 \%$ E.C., these set of fungicides showed a moderate efficient in reducing the disease incidence and disease severity. However, other fungicides i.e., Vectra 10\% S.C., Fungshow 12.50\% W.P., Score 25\% E.C., Tecto 50\% S.C., Rovral $50 \%$ W.P., Rizolex T 50\% W.P., Ridomil Gold/Plus $42.50 \%$ W.P., Copral 50\% W.P., Eminent $12.50 \%$ E.W. and Thiovat Jet $80 \%$ W.G. showed a least efficient in reducing the disease incidence and disease severity of Botryodiplodia theobromae Pat. (isolate code No., Q.K.4.). The former results were also similar like those obtained by Ansar, 1994, Dwivedi and Dwivedi, 1994, Majumdar and Pathak, 1997, Banik et al 1998, Baiuomy et al 2003, Khanzada et al 2005, Bokhari et al 2008, Abd El-Aziz et al 2010, Kamhawy, 2011, Korra, et al 2014 and Asma Safdar et al 2015.

Information about cultivar reaction of guava transplants against Botryodiplodia theobromae is still scanty. Cultivar reaction of guava trees is one of the most important factors affecting percentage of disease incidence and disease severity of guava die-back disease, were evaluated. Obtained data showed that all tested cultivars were susceptible but they revealed different reaction to each Botryodiplodia theobromae Pat. isolates. There was a clear rating for the 4 cultivars of guava according to their response to infection with Botryodiplodia theobromae Pat. isolates. This rating figured that Banaty cultivar was most susceptible, meanwhile Malisy Ahmar and El-mobaker were moderate susceptible, Gizy Ahmr was lowest susceptible as they recorded the initial disease incidence and disease severity after 60 days after soil infestation. The variation between reactions of guava cultivars may be due to the differences in their morphological, anatomical structures and chemical components, contrary reaction that occurred against Botryodiplodia theobromae Pat. isolates infection.

\section{REFERENCES}

Abd El-Aziz, A.S., Sahar M. El-Baz and Kamhawy M.A.M. 2010. Mango die back disease in Egypt and its control. Egypt J. of Appl. Sci., 25 (10A), 417-433.

Abdel-Gawad, T.I. 2000. Anthracnose fruit rot disease of guava in El-Minia, Egypt. Assiut Journal of Agricultural Sciences, 31 (4), 89107.

Adisa, V. 1985. Fruit rot diseases of guava (Psidium guajava L.) in Nigeria. Indian Phytopathol., 38(3), 427-430.

Anonymous, 2009. Statistical analysis system, SAS user's Guide: Statistics. SAS institute. Inc. Ed., Cary, North Carolina, USA.

Ansar, M., Saleem A. and Iqbal A. 1994. Cause and control of guava decline in the Punjab ( $\mathrm{Pa}-$ kistan). Pakistan J. of Phytopathology, 6 (1), 41-44.

Baiuomy, M.A.M., Kamhawy M.A.M., El-Shemy H.A. and Mustafa Z.M.M. 2003. Root-rot of 
guava and its control in Egypt. Zagazig J. Agric. Res., 30(3), 801-817.

Banik, A.K., Kaiser S.A.K.M. and Dhua R.S. 1998. Evaluation of some systemic and nonsystemic fungicides against Botryodiplodia theobromae, the cause of dieback disease of mango (Mangifera indica L.). J. Soils Crops, 8, 199-222.

Bokhari, A.A., Sahi S.T., Khan M.A., Ahmad R. and Islam-ud-D. 2008. In vivo studies on the biological and chemical control of guava decline caused by different soil borne pathogens. Pakistan J. of Agricultural Sciences, 45 (1), 54-56.

Cardoso, J.E., Maia C.B. and Pessoa M.N.G. 2002. Occurrence of Pestalotiopsis psidii and Lasiodiplodia theobromae causing stem rot of guava plants in the State of Ceara, Brazil. Fitopatologia Brasileira, 27 (3), 320.

Cooke, B.M., Gareth D.I. and Kaye B. 2006. The epidemiology of plant disease, $2^{\text {nd }}$ ed. (chapter 2, Disease assessment and yield losses, B. M. Cooke) springer, printed in the Netherlands, 583p.

Dharam, V. and Gaur A. 1973. Relative evaluation of some systemic and [other] fungicides for the control of anthracnose of guava. Pesticides, Bombay, 7 (5), 15- 22.

Dwivedi, Neetu and Dwivedi S.K. 2016. Histopathological observations in guava root during wilting caused by Fusarium species: a scanning electron microscopy study. International J. of Fruit Science, 16 (3), 335-340.

Dwivedi, S. K. and Dwivedi R. S. 1994. Population dynamics of guava (Psidium guajava L.) wilt pathogens in pesticides treated soil. International J. of Tropical Plant Diseases, 12 (2), 187-195.

Junqueira, N.T.V., de Andrade L.R.M., Pereira M., Lima M.M. and da C. Chaves R. 2001. Diseases of guava (Psidium guajava L.) cultivated in Brazilian Cerrados. Circular Tecnica Embrapa Cerrados, (15), 31.

Kamhawy, M.A. 2011. Correlation of stem canker disease, caused by Botryodiplodia theobromae Pat. and die back symptoms on guava trees; and practical solutions for disease control. J. Biol. Chem. Environ. Sci., 6(4), 184-198.

Khanzada, M.A., Lodhi A.M. and Shahzad S. 2005. Chemical control of Lasiodiplodia theobromae, the causal agent of mango decline in Sindh. Pakistanian J. of Botany, 37 (4), 10231030.
Korra, A.M.K., Abd El-Aziz A.S., Azza M.K. Azmy, Rashed M.F. and Soad A.M. 2014. Survey, incidence and chemical control against Lasiodiplodia theobromae, the causative fungus of die-back, blossoms blight and stem end rot of Mangifera indica. J. Biol. Chem. Environ. Sci., 9 (2), 35-55.

Li, Hong-Ye, Cao R.B. and Mu Y.T. 1995. In vitro inhibition of Botryospheria dothidea and Lasiodiplodia theobromae, and chemical control of gummosis diseases of Japanese apricot and peach trees in Zhejiang province, China. Crop Prot., 14, 187-191.

Majumdar, V.L. and Pathak V.N. 1997. Control of fruit rots of guava by chemical fungicides. J. of Mycology and Plant Pathology, 27 (1), 17-20.

Mishra, N.K., Someshwar B., and Sitansu P. 2009. In vitro evaluation of toxic metabolites produced by some foliar pathogens of guava (Psidium guajava L.). J. of Mycopathological Research, 47 (1),37-41.

Mishra, N.K. and Pan S. 2007. Studies on some nutritional factors on growth and sporulation of three foliar pathogens of guava (Psidium guajava L.). J. of Interacademicia, 11(4), 424431.

Nunes, F.M., deOliveira M. da C.F., Arriaga A.M.C., Lemos T.L.G., Andrade Neto, de Mattos M.C., Mafezoli J., Viana F.M.P., Ferreira V.M., Rodrigues Filho and Ferreira A.G. 2008. A new eremophilane type sesquiterpene from the phytopatogen fungus Lasiodiplodia theobromae (Sphaeropsidaceae). J. of the Brazilian Chemical Society, 19 (3), 478-482.

Pandit, P.K. and Samajpati N. 2005. Wilt disease of guava caused by Botryodiplodia theobromae Pat. J. of Mycopathological Research, 43 (1), 41-43.

Pandit, P.K. and Samajpati N. 2002. Wilt disease of guava (Psidium guajava L.) by Botryodiplodia theobromae Pat. J. of Mycopathological Research, 40 (1), 71-73.

Rana, O. 1981. Diplodia stem canker, a new disease of guava. Pradesh india Sci. \& Cult., 47, (10), 370-371.

Rashed, M.F., Abd El Aziz A.S., Korra A.K.M. and Kamhawy M.A.M. 2014. Observation on anatomical changes in guava leaf (Psidium guajava L.) infected with Colletotrichum gloeosporioides Penz and Sacc., the causal agent of anthracnose during host pathogen interaction. J. Biol. Chem. Environ. Sci., 9 (1), 21-33.

Rawal, R. D. and Ullasa B.A. 1988. Management of fruit diseases of guava (Psidium guajava) 
through fungicidal sprays. Indian J. of Agricultural Sciences, 58 (12), 950-952.

Safdar, Asma, Khan S.A. and Safdar M.A. 2015. Pathogenic association and management of Botryodiplodia theobromae in guava orchards at Sheikhupura District, Pakistan. International J. of Agriculture and Biology, 17(2), 297-304.

Sharvell, E.G. 1962. The nature and uses of modern fungicides. Progress publishing company. Minneapolis, U.S.A. 202 p.
Sitansu, P. and Mishra N.K. 2010. Epidemiological studies on some diseases of guava (Psidium guajava L.). The J. of Plant Protection Sciences, 2 (2), 49-52.

Steel, R.G.D., Torrie J. H. and Dickey D.A. 1997. Principals and Procedures of Statistics: A Biometric Approach, $3^{\text {rd }}$ Ed. McGrawHill Book Co. Inc. New York, USA.

Topps, J. H. and Wain R. L. 1957. Investigation on fungicides III. The fungi toxicity of 3 and 5 alkyl-Salicylanilides and Parachloroamilides. Ann. Appl. Biol., 45, 506-541. 
المؤتمر الرابع عشر لبحوث التنمية الزراعية،

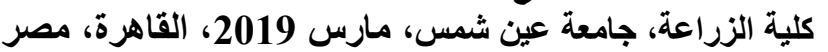

مجلا(27)، عدد (1)، عدد خاص مارس، مارس

Website: http://strategy-plan.asu.edu.eg/AUJASCI/

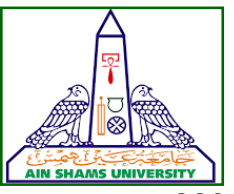

823

المكافحة الكيميائية للموت الرجعى على الجوافه و رد فعل أصناف الجوافه للمرض في مصر

[73]

\author{
عاطف صبري عبد العزيز \\ معهد بحوث أمراض النبات- مركز البحوث الزراعية- الجيزة- مصر لعزيز
}

"Corresponding author: ahmed.sabry617@gmail.com

Received 30 January, 2019,

Accepted 11 March, 2019

Ridomil Gold/Plus في حين أظهرت المبيدات

Eminent ،Copral 50\% W.P. ، $42.50 \%$ W.P. Thiovat Jet 80\% W.G. ،12.50\% E.W. في إختزال نسبة الإصابة وشدتها. وجد أن طريقة

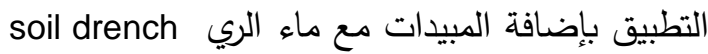

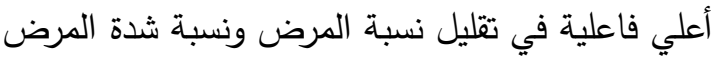

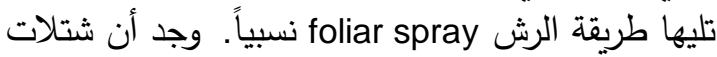

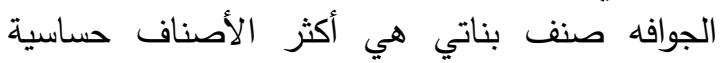

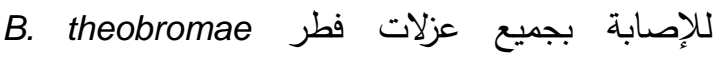

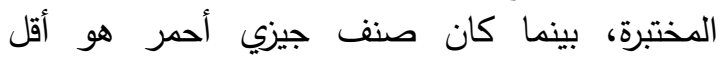
الأصناف حساسية للإصابة بنفس الإنس العزلات العات المختبرة. لاتزال الدراسات السابقة عن رد فعل أصناف الجولة الجوافه ضد فطر B. theobromae ل نادرة.

الكلمات الدالـــــة: جوافة، المكافحة الكيميائيــــة، رد

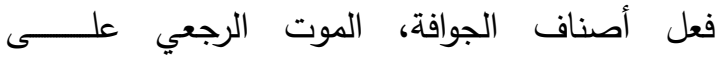

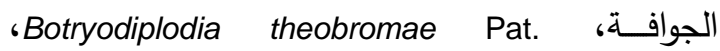
Psidium guajava $\mathrm{L}$.

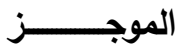

يعتبر مرض الموت الرجعى على الجوافة المتسبب عن الفطر Botryodiplodia theobromae Pat. من الأمراض الهامة والإقتصادية على الجوافة. وقد

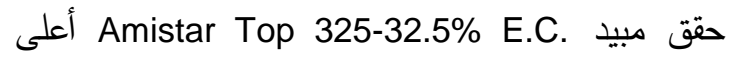
B. إختزال في النمو الطولي وكمية النمو للفطر

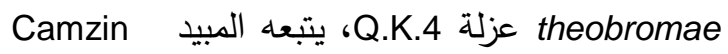
Montro ‘Monceren 25\% W.P. ،50\% W.P. Ridomil 30\% E.C. ،Copral 50\% W.P. ،Gold/Plus $42.50 \%$ W.P. Thiovat Jet $80 \%$ ‘Eminent $12.50 \%$ E.W. أقل كفاءة في إختزال النمو الطولي وكمية النمو

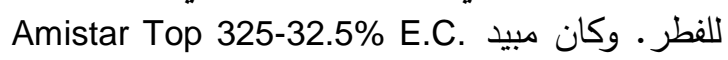
هو أكثر المبيدات كفاءة في إختزال نسبة الإصابة

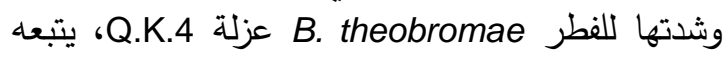
Monceren 25\% المبيد 20amzin 50\% W.P. .Montro 30\% E.C. ،W.P. 